\title{
Conscious intention to speak proactively facilitates lexical access during overt object naming
}

\author{
Kristof Strijkers ${ }^{a},{ }^{\star}$, Phillip J. Holcomb ${ }^{b}$, and Albert Costac \\ aUniversitat de Barcelona, Dept. Psicologia Bàsica, Vall D’Hebron 171, Barcelona 08035, Spain \\ bTufts University, Dept. of Psychology, Medford, MA 02155, USA \\ 'Universitat Pompeu Fabra, Dept. de Tecnologia, ICREA, Barcelona 08018, Spain
}

\begin{abstract}
The present study explored when and how the top-down intention to speak influences the language production process. We did so by comparing the brain's electrical response for a variable known to affect lexical access, namely word frequency, during overt object naming and non-verbal object categorization. We found that during naming, the event-related brain potentials elicited for objects with low frequency names started to diverge from those with high frequency names as early as $152 \mathrm{~ms}$ after stimulus onset, while during non-verbal categorization the same frequency comparison appeared $200 \mathrm{~ms}$ later eliciting a qualitatively different brain response. Thus, only when participants had the conscious intention to name an object the brain rapidly engaged in lexical access. The data offer evidence that top-down intention to speak proactively facilitates the activation of words related to perceived objects.
\end{abstract}

\section{Keywords}

Language production; Lexical access; Task intention; ERPs; Top-down processing

\section{Introduction}

Speaking is primarily an intentional activity: An interlocutor can voluntarily decide whether or not to utter the ideas and thoughts he holds in mind, respond to the speech of others or refer to the objects present in the environment. How does this intention to speak affect the way words are activated and retrieved from memory for eventual production? Despite various studies indicating that some lexical knowledge becomes available even for items we do not intend to name, a deep understanding of when and how the top-down intention to speak acts upon the processing of linguistic information is still lacking. Here, we aim at addressing the influence intention-driven processes might exert on the temporal brain dynamics of lexical access. To do so, we assess the effects of word frequency, as a proxy of lexical activity, on event-related brain potentials (ERPs) in a task involving the intention to speak (object naming) and in a task where no naming intention is present (object categorization).

Investigating the interaction between top-down intention and language processing is quite timely given recent developments, especially in vision and object recognition, highlighting the early involvement of top-down processes. In those fields evidence is accumulating that

(C) 2011 Elsevier Inc. All rights reserved.

"Corresponding author. Kristof.Strijkers@gmail.com (K. Strijkers). 
the brain is not just a passive processor which propagates information in an unidirectional manner, but rather is a collection of dynamical systems actively involved in the construction of cognition (e.g., Desimone \& Duncan, 1995; Engel, Fries, \& Singer, 2001; Gilbert \& Sigman, 2007; Kanwisher \& Wojciulik, 2000; Kastner \& Ungerleider, 2000; Ullman, 1995). Indeed, various studies have shown that top-down influences (e.g., attention, context, intention) produce early and immediate effects on the sensory processing stream (e.g., Corbetta, Miezin, Dobmeyer, Shulman, \& Petersen, 1990; Hillyard, Vogel, \& Luck, 1998; Posner \& Dehaene, 1994) and, in some cases, even trigger task-relevant representations prior to the arrival of the sensory-evoked activity (referred to as proactive top-down processing; e.g., Bar et al., 2006; Kastner, Pinsk, De Weerd, Desimone, \& Ungerleider, 1999; Luck, Chelazzi, Hillyard, \& Desimone, 1997; O’Craven \& Kanwisher, 2000; Peelen, Fei-Fei, \& Kastner, 2009).

Similar attempts in the field of language production are scarce. To clarify, we do not address how speech intention (intention behind the message a speaker wishes to convey) comes about, or how it shapes conceptual processing. Instead, we explore how the intention to speak (the conscious intention to produce language) impacts the flow of information between already activated semantic representations and lexical representations. Thus, to avoid confusion, the term feedforward processing is referred to here as the unidirectional transmission of information from the semantic to the lexical system. The term top-down processing refers to task intentional (or attentional) mechanisms which may or may not affect the feedforward flow between concepts and words. The latter will be investigated by comparing brain activity in two tasks that rely on similar picture processing operations, object naming and object categorization, but differ on the degree to which they require speech production (e.g., Eddy, Schmid, \& Holcomb, 2006). In particular, we will assess to what extent the word frequency effect varies in function of the intention to speak.

\section{Lexical access through feedforward spreading activation}

Most researchers agree that access to words during speech production is achieved through feedforward spreading activation; a principle according to which information necessarily circulates between strongly connected representations (e.g., Collins \& Loftus, 1975; Neely, 1977). For speech production this implies that activated semantic representations spread activation to the corresponding lexical items which a speaker intends to utter (e.g., Caramazza, 1997; Dell, 1986; Dell \& O'Seaghdha, 1992; Levelt, Roelofs, \& Meyer, 1999; Roelofs, 1992; Roelofs, 2003). With the exception of models developed to account for interference induced by target-irrelevant stimuli (e.g., Roelofs, 1992; Roelofs, 2003; see also Cohen, Dunbar, \& McClelland, 1990), understandably most models of speech production remain silent about the consequences of conceptual activation in the absence of the intention to speak. Nevertheless, according to the dynamical principle of spreading activation some lexical information should also become activated even when there is no speech. This is because spreading activation models of lexical access assume a direct link between the semantic and language system, regardless the intention to speak (e.g., Caramazza, 1997; Dell, 1986; Levelt et al., 1999). In this view, a linguistic goal such as the intention to speak (as opposed to a semantic goal such as intention of the message itself) affects the lexicalization process only after this initial link is formed (referred to as reactive top-down processes).

Most of the evidence supporting spreading activation models of lexical access comes from Stroop-like tasks where linguistic influences of distractor words or pictures we do not intend to verbalize affect the speed of target naming (e.g., Costa \& Caramazza, 2002; Cutting \& Ferreira, 1999; Damian \& Bowers, 2003; Glaser \& Glaser, 1989; Griffin \& Bock, 1998; Levelt et al., 1991; Meyer \& Damian, 2007; Morsella \& Miozzo, 2002; Navarrete \& Costa, 2005; Morgan \& Meyer, 2005; Peterson \& Savoy, 1998; Roelofs, 1992; Roelofs, 2003; 
Roelofs, 2006; Roelofs, 2008). Particularly compelling are the contextual effects produced by to-be-ignored pictures, since both the target and the distractor need to be conceptually processed in order to retrieve words (e.g., Bles \& Jansma, 2008; Glaser \& Glaser, 1989; Meyer \& Damian, 2007; Morsella \& Miozzo, 2002; Navarrete \& Costa, 2005). For instance, a target picture DOG simultaneously presented with a phonologically related distractor picture doll results in faster naming latencies as compared to when presented with an unrelated distractor (coat). Researchers explained these and related findings in terms of parallel activation of the linguistic system for both the speech intended and nonintended object; a result which is consistent with the notion of spreading activation between representational systems. However, some studies have failed to replicate this pattern of results or demonstrated that the contextual effects only occur under certain circumstances (e.g., Damian \& Bowers, 2003; Jescheniak, Schriefers, Garrett, \& Friederici, 2002; Jescheniak et al., 2009; Oppermann, Jescheniak, \& Schriefers, 2008; Oppermann, Jescheniak, Schriefers, \& Gorges, 2010). Others have found effects in the opposite direction (e.g., Bloem \& La Heij, 2003; Bloem, van der Boogaard, \& La Heij, 2004), which has been interpreted as favoring another class of speech production models, namely concept selection models, where only those concepts one intends to utter will percolate to the lexicon (e.g., Bloem \& La Heij, 2003; Levelt, 1989).

Furthermore, in all of the above studies a naming response was still required, leaving open the question of whether activated concepts trigger lexical knowledge even when a task does not involve speaking at all. The available evidence here, which is based on registering linguistic effects in non-verbal tasks, is scarce and controversial. For example, some authors have found that a lexical variable such as word frequency affects the speed of semantic categorization, suggesting that words receive some input from semantic representations even when there is no intention to speak (e.g., Kroll \& Potter, 1984). However, this finding does not seem very robust and most studies have failed to replicate it (e.g., Jescheniak \& Levelt, 1994; Morrison, Ellis, \& Quinlan, 1992; Wingfield, 1968). Similarly, while Schiefers et al. (1990; see also Levelt et al., 1999) consistently found semantic interference from distractor stimuli during picture naming, those effects were absent during a non-verbal old/new picture judgment task. Notwithstanding, whether or not a linguistic manipulation affects the speed of a non-linguistic response says little about the presence or absence of lexical activity in a non-verbal task.

A recent fMRI study of the picture (distractor) - picture (target) paradigm provides an illustrative example of this logic (Bles \& Jansma, 2008). Target and distractor pictures which activated brain areas thought to be involved in phonological processes during a phoneme detection task also became active during a semantic categorization task. However, a phonological relatedness effect between targets and distractors in both the reaction times and the fMRI data was only found for the phonological task. In other words, even though language-related information became available in a non-linguistic task, it seemed to influence the brain and behavior in a different manner as during a task which explicitly required language processing. By itself this is not so surprising. Models incorporating spreading activation merely suppose that an activated concept percolates to the lexicon, regardless whether the task is verbal or not. They do not assume that the speaker's behavior or overall brain response to a linguistic manipulation should be similar for verbal and nonverbal tasks. The question here is not whether verbalizing a concept or not is different, but when it is different. Reaction times and the BOLD response lack the temporal resolution to determine at which point during processing the necessary differences between naming and categorization occur.

The few studies in the language production literature which do employ time-sensitive techniques capable of tracing language processing online, such as ERPs (e.g., Holcomb \& 
Grainger, 2006; Kutas \& Federmeier, 2000; Kutas \& Hillyard, 1980) and eye tracking (e.g., Griffin \& Bock, 2000), also have yielded inconclusive and contradicting results about whether objects activate the language system in non-verbal tasks. Meyer, Sleiderink, and Levelt (1998) encountered a lexical frequency effect in a picture naming task for both reaction times and amount of viewing times as registered with eye tracking. During a subsequent object/non-object decision task no lexical frequency effects were found for either measure. The authors concluded that objects in a visual task are not processed up to phonology. AlsoJescheniak et al. (2002) reached the same conclusion based on the presence of a phonological relatedness effect in the ERPs between distractors and targets in a naming task, which was absent in a non-verbal size judgment task. In contrast, Meyer, Belke, Telling, and Humphreys (2007; see also Belke, Humphreys, Watson, Meyer, \& Telling, 2008) showed in an eye tracking study that phonologically related picture distractors resulted in increased error-rates and incorrect eye-saccades when visually searching for a target picture. Based on these findings they argued that the mere visual presentation of an object results in phonological activation. With respect to the role of the intention to speak for lexical access several problems of these studies have to be pointed out. First, aside from displaying contradicting results, none of these studies were able to unambiguously pinpoint the locus of their observed effects to a particular linguistic or conceptual processing stage (Jescheniak et al., 2002; Meyer et al., 1998; Meyer et al., 2007). Second, the non-verbal tasks were all related to physical judgments about the objects. The semantic analyses might be too superficial in this case to engage the link between concepts and words (e.g., Bles \& Jansma, 2008). The data are specially relevant for understanding whether a perceived object is automatically associated with a verbal label (e.g., Griffin, 2004; Humphreys, Riddoch, \& Price, 1997; and see for a similar debate in spoken word recognition whether listeners can pre-activate the names of objects in the visual world paradigm e.g., Allopenna, Magnuson, \& Tanenhaus, 1998; Dahan \& Tanenhaus, 2005; Huettig \& McQueen, 2007; Tanenhaus, Magnuson, Dahan, \& Chambers, 2000), but they do not necessarily relate to the dynamics between concepts and words or how the intention to speak may influence this lexicalization process.

\section{To speak or not to speak: The present study}

Most of the reviewed studies above show that distractors, objects a speaker does not intend to utter, nonetheless activate lexical information in picture naming. Whether this is also the case in non-verbal tasks is much less clear. One factor which seems to be of importance is the depth of semantic processing required in the non-verbal tasks (e.g., Bles \& Jansma, 2008). This is important for the present purposes. Whether guiding attention towards objects is sufficient to generate lexical activation is an interesting issue, but it is not the one at stake in differentiating between the mechanisms of lexical access and the role of intention to speak. Speech production models which embrace spreading activation assign this principle between concepts and words, not necessarily between objects and words. From here the prediction follows that at least some lexical knowledge should become available in nonverbal tasks demanding sufficient semantic processing. As reviewed above, only a few demonstrations of the latter are available in the literature. And even those studies showing language related activation in conceptual tasks (e.g., Bles \& Jansma, 2008; Kroll \& Potter, 1984; Meyer et al., 2007), lack the temporal accuracy to inform us about when the automatic spread of activation is influenced by the conscious intention to speak (this also holds for the discussed eye-tracking studies, since their time course is relevant from target presentationspoken or visual-onwards, but not for the prior presented prime or distractors). To this end, here we will explore whether lexical access is entailed in a nonverbal semantic task, and if so, whether the manner in which lexical access is achieved when there is no naming intention can be considered quantitatively and/or qualitatively similar as during intended speech production. 
In order to obtain explicit temporal information of the online processes involved in speech production, the EEG is registered while participants are instructed to immediately respond upon object presentation; also in the overt naming task. Such immediate object naming setup with EEG recordings only recently has been employed successfully in order to study language production (e.g., Christoffels, Firk, \& Schiller, 2007; Costa, Strijkers, Martin, \& Thierry, 2009; Koester \& Schiller, 2008; Strijkers, Costa, \& Thierry, 2010; Verhoef, Roelofs, \& Chwilla, 2009). A particularly relevant observation for the present goals is that variables known to affect the speed with which we retrieve words (e.g., lexical frequency, semantic interference, first vs. second language speech), have been shown to produce deflections in electrical brain activity within $200 \mathrm{~ms}$ after picture onset (Costa et al., 2009; Strijkers et al., 2010). In a positive going waveform (P2) ERP amplitudes increased as a function of naming difficulty. We must point out that the underlying functionality of this P2 deflection is unclear and we certainly do not wish to claim that it reflects the process of lexical access by itself. In fact, P2 modulations have been reported before in language comprehension studies illustrating sensitivity to anticipatory effects, phonological priming and word class (e.g., Federmeier, 2007; O'Hare, Dien, Waterson \& Savage, 2008; ter Keurs, Brown, Hagoort, \& Stegeman, 1999). Most of these studies have related the P2 effects to the ones encountered in visual attention, namely a modulation engendered by an attentiondriven analysis related to the physical properties of a visual stimulus (e.g., Luck \& Hillyard, 1994). Interestingly and in contrast to the visual $P 2$, the one elicited for lexical variables in naming is found when the manipulated lexical variable bares no difference between the conditions with respect to physical or conceptual attributes and even when stemming from the same visual input (Costa et al., 2009; Strijkers et al., 2010). These findings in combination with the different scalp distribution of the P2 in naming, makes it possible that the lexical sensitive P2 is different from the exogenous P2 (we will come back to this issue in the 'General discussion'). To at least acknowledge this possibility we will label the P2 observed in naming tasks for now the production P2 (pP2). Let us stress again that this does not mean that the mechanism responsible for the $\mathrm{pP} 2$ will only become apparent in production tasks or that it is the direct expression of lexical access for that matter. Whatever process may drive this ERP modulation, of importance here is that this process is sensitive to lexical manipulations, making it a useful instrument to explore the dynamics of lexical access in picture naming tasks.

The rationale behind the experiments is based on the combination of the theoretical framework provided by the language production models embracing spreading activation as main principle of lexical access with the above reported pP2 modulations to lexical variables. Comparing the nature of the pP2 deflection between object naming and object categorization should enable us to directly investigate whether lexical access is apparent in a task which does not require speech and if so, whether it can be considered similar in both tasks. In order to tap into lexical processing and elicit a pP2 modulation we chose to manipulate the lexical frequency of the objects' names (see Strijkers et al., 2010). The lexical frequency effect refers to the observation that naming latencies are faster for objects with names we produce on a regular basis compared to objects with names we produce rarely. Crucially, this effect is thought to arise at the moment the brain starts retrieving word information (e.g., Almeida, Knobel, Finkbeiner, \& Caramazza, 2007; Caramazza, Costa, Miozzo, \& Bi, 2001; Graves, Grabowski, Mehta, \& Gordon, 2007; Kittredge, Dell, Verkuilen, \& Schwartz, 2007; Knobel, Finkbeiner, \& Caramazza, 2008; Navarrete, Basagni, Alario, \& Costa, 2006; Strijkers et al., 2010).

Tracking the time-course of the lexical frequency effect during a task that involves the intention to name and a task that lacks naming intention generates the following predictions: If concepts trigger the initial activation of words in a feedforward fashion independently of a speaker's intention (e.g., Caramazza, 1997; Dell, 1986; Dell \& O’Seaghdha, 1992; Levelt et 
al., 1999; Roelofs, 1992; Roelofs, 2003), then both object naming and object categorization should elicit the frequency effect in the ERPs under the form of an early pP2 modulation. If, on the other hand, the brain's rapid translation of a visual stimulus into word-related activity is facilitated by top-down intention to speak, then we should observe an early divergence between low and high frequency ERPs only in the case of object naming. If the latter turns out to be true, two possibilities with respect to the frequency effect in object categorization remain. First, there might be no frequency effect visible in the ERPs. This would be problematic for the principle of spreading activation and would provide evidence favoring concept selection models (e.g., Bloem \& La Heij, 2003; Levelt, 1989). The other option is that the lexical frequency effect appears at a later point in time, which would preserve the notion of spreading activation. In this case two ERP expressions of the frequency effect related to quantitative or qualitative differences in lexical access are possible. Or the same pP2 effect is encountered but delayed in time, which would mean that lexical access in object naming and object categorization results from the same spreading activation mechanism, but that the intention to speak can speed up this mechanism for naming. Alternatively, if a different ERP frequency effect presents itself during object categorization, this would mean that lexical access is achieved in a qualitatively different manner when there is intention to speak. That is, a top-down driven lexical access in naming and a "spillover" lexical access due to spreading activation in categorization.

\section{Experiment 1: The lexical frequency effect in object naming}

\section{Methods}

Participants-Twenty participants took part in the experiment. All were students at Tufts University (ages 18-26; 8 males, 12 females) and native speakers of English. All were righthanded, had normal or corrected-to-normal vision and did not suffer from any neurological or motor problems.

Stimuli-We selected 310 simple white line drawings (presented on a black background) representing different objects belonging to various semantic categories. A 170 of them were target pictures, the remaining 140 pictures were fillers and/or go-trials in Experiment 2 (see below). For the 170 target objects the lexical word frequency of their names was manipulated, in that 85 corresponded to low frequency names (mean lexical frequency taken from the CELEX database: 7.0 ) and 85 corresponded to high frequency names (mean lexical frequency: 101.7). Between the low and high frequency groups of object names we controlled for word length (mean letter length: low frequency: 5.1; high frequency: $4.9 ; F<$ 1), name agreement (low frequency: 83\%; high frequency: 89\%; $p>.1$; from Snodgrass \& Vanderwart, 1980) and distribution of the number of members belonging to the same semantic category. All pictures used in the experiment measured on average $5.84 \mathrm{~cm}^{2}$ $\left( \pm 1.29 \mathrm{~cm}^{2}\right)$. The 310 pictures were randomly assigned to an experimental list with the single constraint that members belonging to the same semantic category were more or less equally distributed throughout the list. The latter was achieved by dividing the experimental list in 3 parts (100 first items, 110 middle items and 100 last items) and ensuring that approximately the same amount of members of a semantic category appeared in the 3 parts (for example, there were 16 items belonging to the category mammals; 5 appeared in the first part, 5 in the middle and 6 in the last part of the list).

Procedure-Participants were not familiarized with the object names, but all pictures were repeated once in the same order leading to a total of 620 trials (block 1: 1st presentation of the 310 pictures; block 2: 2nd presentation of the 310 pictures). This was done to fully explore the effect of repetition and its potential interaction with the variable of interest, namely lexical word frequency. Participants were asked to name the pictures aloud as fast 
and accurately as possible. Their response was registered by a voice key in a soundproof room. An experimental trial had the following structure: (a) an object was presented for 350 $\mathrm{ms}$ in the center of a computer screen; (b) a blank interval of $1750 \mathrm{~ms}$ intervened between the offset of the object and the start of a new trial. Breaks of 5-15 s were administered randomly after 15-30 object naming trials and there was a break of at least 1 min between blocks 1 and 2 of the experiment.

EEG recording procedure-The electroencephalogram (EEG) was recorded from 28 tin electrodes embedded in an elastic cap (Electrode-Cap International) and placed on the scalp of the participants. Additional electrodes were attached below the left eye (LE, to monitor for vertical eye movement/blinks), to the right of the right eye (VE, to monitor for horizontal eye movements), over the left mastoid bone (A1, reference) and over the right mastoid bone (A2, recorded actively to monitor for differential mastoid activity). All EEG electrode impedances were maintained below $5 \mathrm{kX}$ (impedance for eye electrodes was less than $10 \mathrm{kX}$ and for the reference electrodes less than $2 \mathrm{kX}$ ). The EEG was amplified by an SA Bioamplifier with a bandpass of 0.01 and $40 \mathrm{~Hz}$ and the EEG was continuously sampled at a rate of $250 \mathrm{~Hz}$ throughout the experiment.

Data analysis-The raw EEG was segmented off-line in epochs of $650 \mathrm{~ms}$ starting $100 \mathrm{~ms}$ before stimulus onset until $550 \mathrm{~ms}$ after stimulus onset. All trials containing eye blinks (signals exceeding $\pm 70 \mu \mathrm{V}$ within an epoch) were removed prior to averaging. In addition, trials containing errors (7\%) and trials with naming latencies faster than $550 \mathrm{~ms}(5 \%)$ were excluded from the analyses to avoid contamination of the ERPs caused by muscular and mouth activity (e.g., Costa et al., 2009; Strijkers et al., 2010). The epochs were lowpass filtered at $15 \mathrm{~Hz}$ and averaged together according to the two levels of lexical frequency (high vs. low) and the two levels of presentation (first vs. second). All averaged data were baseline corrected utilizing the $100 \mathrm{~ms}$ prior to stimulus presentation. For the analyses various electrodes were clustered together dividing the scalp in 7 regions: Left FrontoCentral (LFC: F3, F7, FC5, T3), Frontal (Fr: Fz, FC1, FC2), Right FrontoCentral (RFC: F4, F8, FC6, T4), Left CentroParietal (LCP: C3, CP5, P3, T5), CentroParietal (CP: $\mathrm{Cz}, \mathrm{CP} 1, \mathrm{CP}$ 2, Pz), Right CentroParietal (RCP: C4, CP6, P4, T6) and Occipital (Oc: O1, Oz, O2). Two types of analyses were conducted on the ERP data. First, classical peak amplitude analyses were performed on six time-windows containing visible peaks: [0-70 ms] (P1 peak), [70-140 ms] (N1), [140-210 ms] (pP2), [210-280 ms], [280-350 ms], [350-500 ms]. Separate 2 (frequency) $\times 2$ (repetition) $\times 7$ (electrode cluster) repeated measures analyses of variance (ANOVAs) were used to analyze the data in all six time-windows. Where necessary, Geisser and Greenhouse correction and Bonferonni correction for multiple comparisons were applied. Second, we performed onset latency analyses between ERPs elicited by pictures with low frequency names and those elicited by pictures with high frequency names. We did so by running two-tailed $t$-tests at every sampling point (4 ms) starting from picture onset $(0 \mathrm{~ms})$ until at least a sequence of 12 consecutive $t$-test samples exceeded the 0.05 significance level (e.g., Costa et al., 2009; Guthrie \& Buchwald, 1991; Strijkers et al., 2010; Thierry, Cardebat, \& Demonet, 2003). The first point where a significant row of $12 t$-tests occurred was taken as the onset of the frequency effect.

\section{Results}

The behavioral data displayed significant main effects of frequency (subjects: $F_{1,19}=16.27$, $P=.001$; items: $F_{1,168}=28.77, P<.001$ ) and repetition (subjects: $F_{1,19}=68.92, P<.001$; items: $\left.F_{1,168}=134.65, P<.001\right)$, and a significant interaction between frequency and repetition (subjects: $F_{1,19}=12.91, P=.002$; items: $F_{1,168}=22.59, P<.001$ ). As can be appreciated in Fig. 1, pictures with high frequency names were uttered faster than pictures 
with low frequency names, and pictures presented for a second time gave rise to faster naming responses compared to the first presentation, especially for low frequency items.

For clarity we will mainly report the ERP results relevant in light of the present study, with a special emphasis for the P2-range [140-210 ms], the time-window of interest (the statistical results for all 6 time-windows and variables analyzed are summarized in Table 1a). There were no significant effects in the earliest time-windows (P1 and N1) for any of the variables (all $P S>.1$ ). When comparing the ERPs elicited by low frequency versus high frequency items, the first differences became significant in the $\mathrm{P} 2$ range $\left(F_{1,19}=9.85, P=.005\right)$. ERPs to pictures with low frequency names had more positive amplitudes between 140-210 ms than ERPs to pictures with high frequency names (see Fig. 2a). We also encountered a significant main effect of repetition on the $\mathrm{P} 2$ amplitude $\left(F_{1,19}=5.51, P<.05\right)$. The $\mathrm{P} 2$ was more positive for objects presented a second time compared to the first presentation (see Fig. $2 b$ ). Importantly, the data also showed a significant interaction between repetition and electrode cluster $\left(F_{6,114}=3.60, P<.05\right)$ and a significant three-way interaction between frequency, repetition and electrode cluster $\left(F_{6,114}=3.72, P<.05\right)$. $T$-tests of the various contrasts revealed that the $\mathrm{P} 2$ frequency effect interacted with repetition but only for the LFC, Fr and RFC electrode clusters (see Fig. 3). At posterior regions (CP, LCP) the significant frequency effect was unaffected by the repetition of items (see Fig. 3).

Furthermore, we also observed significant interactions of frequency with electrode cluster in the [280-350 ms] range and the [350-500 ms] range (all $P_{S}<.05$ ). $T$-tests showed that for both time-windows ERPs for low frequency items were more positive going (and less negative going) compared to the ERPs for high frequency items at LCP, CP and RCP electrode clusters (all $P S<.05$ ). Finally, we found a main effect of repetition in the [350-500 $\mathrm{ms}$ ] time window with ERPs elicited by the first presentation of the pictures having more negative amplitudes compared to those elicited by the second presentation $(P<.05)$.

The onset latency analysis revealed that low and high frequency ERPs started to diverge significantly and reliably from each other at $152 \mathrm{~ms}$ after picture onset for RFC, LCP, CP, RCP and OC electrode clusters.

\section{Discussion}

The experiment replicated previous ERP findings regarding the onset of lexical access during overt object naming (Strijkers et al., 2010). ERPs elicited by objects with low frequency names produced more positive going amplitudes compared to those elicited by objects with high frequency names in the P2 time-range, with an onset of $152 \mathrm{~ms}$ after picture presentation. Replicating the $\mathrm{pP} 2$ frequency effect during the naming task, and this for another response language and with more experimental stimuli than in the study ofStrijkers et al. (2010), was crucial in order to use this electrophysiological correlate as a tool to explore the potential influence of top-down intention on lexicalization in the subsequent experiment.

In addition, these results also address two important issues regarding the pP2 frequency effect during overt naming tasks: First, they demonstrate that repetition of the stimuli is not responsible for the $\mathrm{pP} 2$ modulation. The frequency effect at the $\mathrm{pP} 2$ was present during the first presentation of the objects (see Fig. 3), where repetition could not have come into play. Second, the effect of repetition itself produced the typical positive shift for the 2nd presentation of the objects (e.g., Grill-Spector, Henson, \& Martin, 2006; Holcomb \& McPherson, 1994; see Fig. 2b). This finding is important when thinking about the validity of using EEG during overt naming to encounter sensory and cognitive relevant brain activity. It could be argued that all the electrophysiological effects of lexical load manipulations during overt naming tasks (e.g., Costa et al., 2009; Strijkers et al., 2010), even the early ones, merely reveal motor preparation activity, with the fastest conditions producing less positive 
preparation responses. If that was true, then there should always be these types of ERP modulations during overt naming when contrasting fast versus slow naming conditions. However, the repetition effect does not fit this pattern as in this case the fastest naming condition (2nd presentation of the items) produced the more positive response compared to the slower condition (1st presentation of the items). This is the same pattern found in nonverbal tasks (e.g., Grill-Spector et al., 2006; Henson, Rylands, Ross, Vuilleumeir, \& Rugg, 2004; Holcomb \& McPherson, 1994; Rugg \& Doyle, 1994; Schendan \& Kutas, 2003). Such finding supports the position that the early ERP effects for lexical frequency are associated with cognitive relevant brain activity rather than an indication of motor preparation.

Furthermore, although both frequency and repetition could potentially affect the same components and hence be sensitive to the same processes, the fact that the pP2 for lexical frequency displays a reverse pattern in the direction of the modulation and elicits a different scalp distribution compared to the repetition P2 (see Fig. 4), may be indicating that they have distinct functionalities. If so, the repetition P2 (and later positive shift) encountered here, could reflect recollection of a previously seen item (thus, explicitly related to the process of repetition), as reported previously in the literature for objects as well as printed words and faces (e.g., Barrett \& Rugg, 1989; Grill-Spector et al., 2006; Henson et al., 2004; Holcomb \& McPherson, 1994; Rugg \& Doyle, 1994; Van Petten, Kutas, Kluender, Mitchiner, \& McIsaac, 1991; Van Petten \& Senkfor, 1996). In contrast, the pP2 for lexical frequency, which is observed without the need of repeated items and thus seems to occur at least to some degree independently from processes directly associated with repetition such as recollection, may be related to the activation of task-relevant features (lexical here).

Having established the validity of the technique and more importantly, having replicated the early onset of a lexical frequency effect during object naming, we now turn to Experiment 2, for which the exact same stimuli were tested but participants had to engage in a go/no-go semantic categorization task. Previous research has shown that this task engages perceptual as well as higher conceptual processing (e.g., Eddy et al., 2006). In addition, aside from the need to process an object well beyond its physical properties, it has been shown that superordinate semantic categorization tasks also inflect the retrieval of the basiclevel concept (e.g., Grill-Spector \& Kanwisher, 2005; Rosch, 1978). This makes the task ideal with respect to the goals of the present study. The crucial question in Experiment 2 was: What will happen to the $\mathrm{pP} 2$ frequency effect when there is no conscious intention to utter the names of the presented objects?

\section{Experiment 2: The lexical frequency effect in go/no-go object categorization}

\section{Methods}

Participants-Eight-teen participants took part in the experiment. All were students at Tufts University (ages 18-24; 7 males, 11 females) and native speakers of English. All were right-handed, had normal or corrected-to-normal vision and did not suffer from any neurological or motor problems.

Stimuli-The stimuli and the experimental presentation list were identical to Experiment 1. However, to ensure sufficient go-trials (see procedure below), 18 extra items belonging to the category food were included. The 18 novel items were randomly assigned to the experimental presentation list of Experiment 1. As in Experiment 1 the experimental list was repeated once in a second block resulting in a total of 656 trials.

Procedure-The whole procedure was identical to the one in Experiment 1. The only difference with Experiment 1 was that participants, instead of object naming, had to perform 
a go/no-go semantic categorization. They were instructed to push a response button as fast as possible whenever they saw an object belonging to the category food (go-trials; we selected the category food given the nice property of this category to consist of a variety of objects with visually distinct features ensuring that decisions could not be based on prototypical canonical features). This was necessary for $16 \%$ of the trials (for a total of 51 objects; 33 belonging to the filler items of Experiment 1 and 18 extra food items included in this experiment). All critical trials (low and high frequency items) corresponded to a no-go response ( 170 of the 279 no-go trials in the list) and were identical to those in Experiment 1.

EEG procedure and data analyses-These were identical to those of Experiment 1.

\section{Results}

An overview of the statistical results for all the ERP analyses can be appreciated in Table $1 b$. For the earliest time-windows there was only a marginally significant interaction effect of repetition with electrode cluster at the $P 1(P=.053)$. However, independent $t$-tests showed that the repetition effect did not reach significance for any of the electrode clusters; there only were trends towards significance for the Fr and RFC electrode clusters $(P<.1)$.

More relevant, the repeated measures ANOVAs revealed that there was no significant effect when comparing the same low versus high frequency items as in Experiment 1 in the $P 2$ range $\left(F_{1,17}<1\right)$ (see Fig. 5a). There were also no significant interactions of frequency with repetition or electrode cluster (all $P S>.1$ ), nor a significant three-way interaction between frequency, repetition and electrode cluster $(P>.6$; see Fig. 6). As in Experiment 1, we did observe a significant main effect of repetition for the $P 2\left(F_{1.17}=8.47, P<.001\right)$ as well as a significant interaction of repetition with electrode cluster $\left(F_{6,102}=4.14, P<.05\right)$. The repetition of the objects elicited a positive shift in the $P 2$-range and this increase in positive amplitudes was more pronounced for LFC, Fr, RFC and CP electrode clusters (see Fig. 5b).

The first significant effects of frequency became apparent in the [280-350 ms] and the [350-500 ms] ranges with significant interactions of frequency and electrode cluster ([280$350 \mathrm{~ms}]: F_{6,102}=4.67, P<.01$; [350-500 ms]: $\left.F_{6,102}=3.46, P<.05\right)$ (see Fig. $5 \mathrm{a}$ and 6 ). $T$ tests showed that this effect reached significance for the Fr electrode cluster $(P<.05)$ in the [280-350 ms] time window and for Fr, RCP and CP electrode clusters at the [350-500 ms] time window (all $P S<.05$ ). In the $[280-350 \mathrm{~ms}]$ range, high frequency ERPs had more positive amplitudes compared to low frequency ERPs for frontal sites and in the [350-500 $\mathrm{ms}$ ] range low frequency ERPs were more negative going compared to high frequency ERPs (see Fig. 5a). We also found significant main effects of repetition in the [280-350 ms] and [350-500 ms] ranges ([280-350 ms]: $F_{1,17}=13.87, P<.001 ;[350-500 \mathrm{~ms}]: F_{1,17}=6.02, P$ $<.05)$. Repetition resulted in a positive shift of the ERPs and this effect was broadly distributed over the scalp (see Fig. 5b and 6). All other possible main or interaction effects did not reach significance (all $P S>.1$; see Table $1 \mathrm{~b}$ and Fig. 6).

The onset latency analyses confirmed the above ANOVAs in that ERPs to pictures with low frequency names started to diverge significantly from those with high frequency names at $352 \mathrm{~ms}$, which is $200 \mathrm{~ms}$ later compared to Experiment 1 (CP electrode cluster: $P<.001$ ).

\section{Discussion}

The important observation in this experiment is the absence of a lexical frequency effect in the $P 2$-range. Instead, the ERPs elicited by objects with low frequency names did not start to diverge from the ERPs elicited by objects with high frequency names until $352 \mathrm{~ms}$ after picture onset. Thus, compared to Experiment 1, when there is no a priori intention to verbalize the presented objects the first signs of lexical frequency are delayed by $200 \mathrm{~ms}$. 
This finding argues against the notion that lexical access is solely achieved through automatic feedforward spread of activation between concepts and words, but instead supports the hypothesis that initial access to the linguistic system is facilitated (at least at the neuronal level) by the intention to produce overt speech. Nonetheless, we still obtained a frequency effect in this non-verbal task, preserving the dynamical principle of spreading activation between distinct representational systems. Interestingly, this later word frequency effect resulted in a different ERP modulation (of opposite polarity), most likely indicating a distinct type of process underlying lexical access in the case of object categorization compared to object naming. Finally, it is important to note that we found remarkably similar timing and polarity effects of repetition in both experiments which supports the argument that both types of tasks are equally sensitive to general picture processing.

In what follows we will focus on the crucial finding of an early lexical frequency effect during object naming compared to a delayed and different one during object categorization and what it may imply for the theoretical models of language production.

\section{General discussion}

In the present experiments we explored how and when the intention to speak affects lexical activation. We did so by comparing an electrophysiological correlate sensitive to lexical access, the pP2 word frequency effect, in a task involving overt speech versus a task that does not. In the naming task word frequency elicited early ERP modulations ( $152 \mathrm{~ms})$ at the point of the $\mathrm{pP} 2$ component, with low frequency items showing more positive amplitudes than high frequency items (see also Sahin, Pinker, Cash, Schomer, \& Halgren, 2009; Strijkers et al., 2010). Importantly, this pP2 modulation was absent for the go/no-go semantic categorization in Experiment 2. Instead, the first modulations associated with frequency were present in the N400-range, with an onset of $352 \mathrm{~ms}$ after picture presentation.

To the extent that the word frequency effect indexes lexical processing in speech production, two main conclusions can be drawn from these results. First, the initiation of lexical access occurs about $200 \mathrm{~ms}$ earlier in object naming than in object categorization. Thus, the topdown intention to verbalize a concept facilitates lexical access as compared to when no such intention is present. This observation suggests that the speed of the feedforward transmission between concepts and words is modulated by higher level top-down processes, such as the goal-directed intention to speak. Second, the way in which lexical access occurred was qualitatively different in the two tasks: Word frequency elicited pP2 modulations in naming and N400-like modulations in categorization. This means that the two tasks not only differ on the speed with which concepts trigger words, but also in the manner that words become activated. As we will describe later, this latter observation reveals that top-down influences in function of naming intention penetrate the lexico-semantic pathway in a proactive fashion, prior to the feedforward spread. That is, while feedforward activation between concepts and words cause lexical activation even in nonverbal tasks (N400 frequency effect; see also e.g., Bles \& Jansma, 2008; Meyer et al., 2007), engaging in lexical access seems to be driven in a proactive manner by the top-down intention to speak. Before specifying how proactive top-down mechanisms can be implemented in speech production models, we will evaluate the reliability of the findings for supporting this conclusion.

\section{Frequency effects, the pP2 modulation and the time course of lexical access}

The above interpretation of our results hinges on the assumption that word frequency effects index lexical access. However, it remains debatable whether this variable exerts it effect at the level of 'lemmas' or 'lexemes'. Notwithstanding, the conclusion that the intention to speak alters the manner of lexicalization holds regardless of which component of lexical 
access is targeted by word frequency ${ }^{1}$ (e.g., Almeida et al., 2007; Caramazza et al., 2001; Dent, Johnston, \& Humphreys, 2008; Graves et al., 2007; Jescheniak \& Levelt, 1994; Kittredge et al., 2007; Knobel et al., 2008; Navarrete et al., 2006; Strijkers et al., 2010). More problematic for our interpretation of the data is that word frequency also tends to correlate with visual and conceptual variables (e.g., Snodgrass \& Vanderwart, 1980). It could be argued that the early frequency effect in the ERPs is driven by the input processes involved in picture naming rather than the lexicalization process itself (e.g., Bates et al., 2003). And although it is difficult to draw comparisons across modalities, it is nevertheless interesting to mention that P2 modulations in other domains have been associated with topdown effects for perceptual processes. In visual search paradigms an enhanced P2 is reported for attended stimuli and target-relevant information, which has been proposed to reflect attention-driven enhancements of perceptual features of the input (e.g., Hillyard \& Munte, 1984; Luck \& Hillyard, 1994; Mangun \& Hillyard, 1995). In language comprehension similar P2 amplitude increases are observed when words are highly expected in a given sentence or for related prime words (e.g., Federmeier, 2007; Federmeier \& Kutas, 2005; Federmeier, Mai, \& Kutas, 2005; Federmeier, Wlotko, De Ochoa-Dewald, \& Kutas 2007). In line with the functionality assigned to the $P 2$ in visual attention, this effect has been proposed to indicate the correspondence between top-down anticipation of the perceptual features of an upcoming word and the actual perceptual features of the presented word (and see also Wlotko and Federmeier (2007) for evidence that these P2 modulations may be engendered by the anticipatory process in isolation). Consequently, in light of the correlated status of word frequency, it seems plausible that the $\mathrm{pP} 2$ modulation elicited by this variable is similar to the visual P2, indexing the input processes related to object naming.

Note however, that in order to explain the absence of a similar effect in the semantic categorization task, the potential visual/conceptual influences at the pP2 in naming still have to be driven by the top-down intention to speak. An explanation of this sort could be invoked here given that naming and categorization impose different conceptual processing demands. While naming requires the individuation of a specific object linked to a to-be expressed lexical item, categorization, in principle, does not. As a consequence, the correlated effect of word frequency might be sensitive to these top-down differences in conceptual demands between both tasks, resulting in an early ERP modulation during naming and a later one during categorization. This is a very interesting possibility that would make our results even more relevant, given that they would indicate that the top-down intention to speak already affects the manner in which we process objects. Despite the merits and appeal of this alternative interpretation, the available evidence regarding the $\mathrm{pP} 2$ in speech production suggests that this component is sensitive to lexical rather than visuoconceptual processes. Let us elaborate a bit more on this point.

Beyond word frequency, three other variables that are supposed to index the ease with which lexical access proceeds have been shown to elicit pP2 modulations. First, the pP2 was demonstrated to be affected by a picture name's cognate status (cognates are translation words with similar form (rata-rat); while non-cognates are dissimilar (raton-mouse); Strijkers et al., 2010). Although cognate status is defined by formal overlap and it is uncorrelated with any perceptual or conceptual variables (e.g.,Costa, Caramazza, \& Sebastian-Galles, 2000; Costa, Santesteban, \& Cano, 2005), it elicited identical pP2 deflections (enhanced for non-cognates) as encountered for the lexical frequency effect

\footnotetext{
${ }^{1}$ Since we did not control for other lexical factors known to correlate with word frequency such as AoA, it is possible that part or all of the $\mathrm{pP} 2$ effects are driven by AoA rather than lexical frequency. However, this potential lexical confound does not compromise the data and interpretations in any way. The conclusion that intention to speak facilitates access to the lexicon stands independently of which lexical load manipulation is truly behind the observations.
} 
(Strijkers et al., 2010; see also Christoffels et al., 2007). ${ }^{2}$ Second, the pP2 displayed sensitivity to differences between first and second language naming in bilinguals. That is, pP2 amplitudes were larger when bilinguals named pictures in their L2 compared to their L1 (Strijkers et al., 2010). Thus, the same pP2 effect which was modulated for lexical betweenitem factors such as word frequency and cognate status, now also appeared for the withinitem manipulation of response language. Given that object recognition and conceptual processing during L1 and L2 naming should be similar (at least for concrete objects in early high proficient bilinguals), it is hard to see how a visuo-conceptual account associated with the $\mathrm{pP} 2$ could accommodate this finding. Third, the $\mathrm{pP} 2$ was modulated in a very consistent manner by the cumulative semantic interference effect (CSIE). The CSIE is a phenomenon where naming responses display a cumulative increase in reaction times (RTs) for each subsequent item belonging to the same semantic category as previously named items (e.g., RTs for hammer < ...pliers < ...saw etc.; e.g., Brown, 1981; Howard, Nickels, Coltheart, \& Cole-Virtue, 2006; Navarrete, Mahon, \& Caramazza, 2010). Current interpretations of this phenomenon agree that the effects induced by the paradigm occur during lexical access (either as an expression of competition or not; e.g., Howard et al., 2006; Navarrete et al., 2010; Oppenheim, Dell, \& Schwartz, 2007; Oppenheim, Dell, \& Schwartz, 2010).Costa et al. (2009) traced the electrophysiological signature of the CSIE and observed a pattern at the pP2 which perfectly mimicked the behavioral responses: For each subsequent ordinal position of a member belonging to the same category there was a cumulative increase in amplitude. Taken together, only a lexical account associated with the pP2 modulations in object naming is able to unambiguously accommodate all of the results reported by Costa et al. (2009) andStrijkers et al. (2010).

Interestingly, and consistent with the above conclusion, the pP2 in naming displays a distinct topography compared to the one reported for the attentional P2 in vision and language comprehension. While the latter has a frontro-central distribution (also when words instead of pictures are used; e.g., Federmeier \& Kutas, 2002), the pP2 in naming is maximal over posterior sites (see also Costa et al., 2009; Strijkers et al., 2010). While these different electrophysiological expressions between both $\mathrm{P} 2$ modulations on their own do not prove anything and the complexity associated with this component certainly goes beyond a simple anterior-posterior differentiation, ${ }^{3}$ it is nevertheless interesting to observe that the $\mathrm{pP} 2$, which is problematic to accommodate with a perceptual account as discussed in the previous paragraph, elicits a different pattern at the scalp compared to the P2 reported in most visual attention and language comprehension studies. In other words, the fact that certain electrophysiological properties between the $\mathrm{pP} 2$ and the perceptual $\mathrm{P} 2$ appear to be different at least increases the likelihood that both components might be reflecting slightly different underlying processes. That is, although both components seem to be related to top-down processes, the $\mathrm{pP} 2$, in contrast to the exogenous $\mathrm{P} 2$, may actually reflect an endogenous

\footnotetext{
${ }^{2}$ All stimuli in the study were rated for familiarity, imageability, typicality and complexity as well as an objective measure of physical variations between the items of the conditions was calculated (the inter-stimulus perceptual variability measure; see Thierry, Martin, Dowing, and Pegna 2007). While lexical frequency did show a small but significant correlation with familiarity (none of the other conceptual and visual measures reached significance), cognate status did not show any correlations with the ratings on the various conceptual dimensions or for the perceptual variability measure.

${ }^{3}$ For instance, modulations related to phonology at a fronto-central distributed P2 have been reported in word comprehension studies (e.g., Carreiras, Vergara, \& Barber, 2005; Lee et al., 2007; but see O'Hare et al., 2008 for claims that this particular P2 effect is likely the early onset of a word N300). Similarly, a few studies observed posterior P2 effects for nonlinguistic manipulations in memory and vision (e.g., Anllo-Vento \& Hillyard, 1996; Dunn, Dunn, Languis, \& Andrews, 1998). Whether all these different P2 expressions can be integrated into a single account is a very difficult exercise given the huge variety in stimuli, manipulations and designs employed over studies and this is well beyond the scope of the present article; nevertheless, a possible hypothesis (purely suggestive), is that they all are associated with top-down anticipatory and/or attentional influences, where the different expressions between studies (either in terms of distribution, domain and/or manipulations) could relate to different representational levels targeted by this anticipatory mechanism. Regardless the variety in P2 effects and whether they underpin a uniform process, of importance here is that the one encountered in naming so far clearly seems to be sensitive to lexical processes and that this lexical sensitive ERP effect is absent when there is no naming intention.
} 
change controlled by linguistic internal features rather than the physical properties of the input. In this manner, the pP2 modulations associated with word frequency for instance would appear to depend on the level of activation of specific items within the lexicon, with representations which are less accessible (low frequency) necessitating additional top-down enhancements compared to more accessible representations (high frequency).

Finally, despite the above discussed findings which strongly reduce the possibility that the pP2 is linked to perceptual or conceptual operations, does the early time course of the component ( 150-200 ms) actually fit a lexical account? This question becomes especially relevant since ERP studies on visual word recognition and object identification have estimated lexical effects and concept retrieval, respectively, to occur roughly around $250 \mathrm{~ms}$ (e.g., Eddy et al., 2006; Grainger \& Holcomb, 2009; Holcomb \& Grainger, 2006; Pylkkanen \& Marantz, 2003; Schendan \& Kutas, 2003; Schendan \& Kutas, 2007; Sitnikova, West, Kuperberg, \& Holcomb, 2006). However, in simpler experimental settings, other ERP studies report time courses for word-related differences consistent with those reported here (e.g., Hauk \& Pulvermuller, 2004; Pulvermüller, Shtyrov, \& Hauk, 2009) and (at least broad) category-related differences between objects around $150 \mathrm{~ms}$ (e.g., Hauk \& et al., 2007; Kirchner \& Thorpe, 2006; Liu, Agam, Madsen, \& Kreiman, 2009; Schendan, Ganis, $\&$ Kutas, 1998; Thorpe, Fize, \& Marlot, 1996; VanRullen \& Thorpe, 2002). Thus, even if $\sim 250 \mathrm{~ms}$ is a more realistic index of the time needed to retrieve a concept associated with an object, such time course does not negate the possibility that in a speech production task the linguistic system can start receiving input within $200 \mathrm{~ms}$. If we assume that (a) information cascades between concepts and words, as most speech production models do, and (b) that top-down intention in a production task will guide the flow of activation rapidly towards lexicalization (though assumption (a) by itself is already sufficient to make the claim), the prediction is to start seeing the first lexical effects in naming before input processing is completed. In other words, if after 150-200 ms the brain has cumulated sufficient (though likely not all) evidence regarding the input to start stimulating potential word candidates in a production task, an early time course for the initiation of lexical processes ( 150-200 ms) in the presence of a later time course for concept selection $(\sim 250 \mathrm{~ms})$ is perfectly reasonable.

Similarly, provided the evidence that the $\mathrm{pP} 2$ modulations in picture naming reflect the first transmission between concepts and words (Strijkers et al., 2010), and at least another $180 \mathrm{~ms}$ from that point until the completion of lexical selection are necessary (whether or not including word forms; Costa et al., 2009), observing later lexical effects $(\sim 250-350 \mathrm{~ms})$ in other paradigms are not necessarily in contradiction with the earlier effects reported here. Moreover, granting the above depicted estimates for respectively the onset and latency of lexical access would leave about 400-500 ms for syllabification, metrical and phonetic encoding, monitoring, motor programming and triggering the articulatory apparatus. This is a highly realistic sequence of temporal events for single word production (e.g., Indefrey \& Levelt, 2004; Maess, Friederici, Damian, Meyer, \& Levelt, 2002; Sahin et al., 2009) and supports the notion that the time course underlying the pP2 fits a lexical account.

\section{Incorporating top-down mechanisms in speech production}

Granting lexical sensitivity of the pP2, in this section we describe which models of speech production best fit our data and how they can be complemented with proactive top-down mechanisms. At first sight, the fact that the pP2 effect is only present when the task involves naming seems to be consistent with concept selection models, which postulate that only under the intention to name will activity be propagated from concepts to words (e.g., Bloem \& La Heij, 2003; Levelt, 1989). However, since in these types of models words are not supposed to get activated in categorization at all, no word frequency effects should be detected. How then can such models accommodate the presence of the N400 effect in categorization? In general, the N400 is an ERP component related to either the prediction, 
integration or both (depending on task and available resources) of lexico-semantic processes in language (e.g., Federmeier, 2007; Hagoort, 2008; Holcomb, 1993; Kutas, 1993; Kutas \& Hillyard, 1980). One possibility for concept selection models to explain the N400 in categorization is by assuming that it reveals semantic effects associated with word frequency and not lexical ones. Nevertheless, most researchers agree that modulations of the N400 involve the lexical network at least to some extent (e.g., DeLong, Urbach, \& Kutas, 2005; Federmeier, 2007; Federmeier \& Kutas, 1999; Grainger \& Holcomb, 2009; Halgren et al., 2002; Holcomb \& Grainger, 2006; Kutas \& Federmeier, 2000; Lau, Phillips, \& Poeppel, 2008). Furthermore, in comprehension a parallel reduction of the N400 for lexical frequency to the one encountered here is typically interpreted as revealing easier lexical integration or prediction for high compared to low frequency words (e.g., Besson, Kutas, \& Van Petten, 1992; Rugg, 1990; Van Petten, 1995; Van Petten \& Kutas, 1990; Van Petten \& Kutas, 1991). Adopting the same lexical account for our data seems the more parsimonious option. But, even if we presume that the word frequency modulation of the N400 in categorization solely indexes conceptual processes, it still remains unclear how concept selection models, which argue that semantic retrieval has to be terminated prior to lexical access, would account for the full set of data reported in our study. That is, why does a semantic effect in categorization occurs so late while a lexical effect in naming is measureable within the first $200 \mathrm{~ms}$ ? At the very least, concept selection models would predict that whatever the semantic effect associated with word frequency reported in categorization, it should also be present in the conceptually more demanding task of naming and, importantly, prior to observing any linguistic-related differences. ${ }^{4}$ This is not what our results indicate.

Models incorporating spreading activation from the semantic to the lexical system appear to be better suited to account for these data. As described in the Introduction, according to these models any activated conceptual representation would lead to activation (at least in part) of its corresponding lexical item. In this scenario, one would expect frequency effects in tasks that require naming but also in non-verbal tasks which require conceptual processing. This is precisely what is observed if one takes the N400 frequency effect as being sensitive to lexical processes. Of course, assigning (at least partially) lexical involvement to the N400 in categorization may invoke the question why we do not observe a similar effect (alongside the pP2) in naming where lexical activation is more fundamental. The most straightforward answer is that the $\mathrm{N} 400$ modulation for word frequency in naming is to some degree being masked by the presence of the $\mathrm{pP} 2$ deflections, where the direction of the frequency effect is the opposite than at the N400. Indeed, if we were to align the high and low frequency waveforms in the P2-range, a very similar N400 modulation of word frequency to the one encountered for categorization would emerge (see Figs. 2 and 3). Secondly, though more an empirical issue, in categorization the task context "is a food", which is absent in naming where there are no uniform response requirements, may have produced additional modulations at the $\mathrm{N} 400$ with low frequency words resulting in a worse mapping onto the task context compared to high frequency words. In any event, the lexical frequency effect at the N400 is most parsimoniously explained by assuming the presence of spreading activation from concepts to words regardless of the intention to speak, as proposed in various models of speech production (e.g., Caramazza, 1997; Dell, 1986; Levelt et al., 1999). To also account for the qualitatively different time-course of the frequency effect between the two tasks the spreading activation principle specified in these models has to be complemented though with a proactive top-down mechanism.

Accounts from visual attention and object recognition offer useful insights about how such a mechanism can be implemented. Early top-down effects in vision are often explained by

\footnotetext{
${ }^{4}$ And recall, as exhaustively discussed in the previous section, that arguing that the $\mathrm{pP} 2$ in naming actually reveals this correlated semantic effect of word frequency is not straightforward, given the type of variables which induce modulations at the pP2.
} 
assuming that the sensory-evoked response for the task-relevant representations is amplified, producing a processing advantage over task-irrelevant representations (e.g., Corbetta et al., 1990; Hillyard et al., 1998; Posner \& Dehaene, 1994). However, an explanation in terms of sensory gain would in principle predict a stronger $\mathrm{pP} 2$ amplitude modulation of the frequency effect in object naming compared to categorization or, alternatively, a delayed pP2 frequency effect for the latter (depending on whether the ERP modulation directly reflects the sensory gain or the consequences of it). In contrast, we observed a qualitatively different time-shift between the frequency effects in both tasks. Such finding necessitates the assumption that the relevant neural populations are tuned prior to the arrival of sensorydriven activity. There are at least two general ways in which top-down signals can bring about the proactive adjustment of task-related neuronal activity.

First, proactive influences can be achieved by either increasing the baseline activity of the lexico-semantic pathway or by strengthening the propagation of information from semantic to lexical representations (similar arguments have been put forward in visual attention, perceptual learning and priming; e.g., Desimone \& Duncan, 1995; Engel et al., 2001; Gilbert \& Sigman, 2007; Kastner et al., 1999; Luck et al., 1997; Naccache, Blandin, \& Dehaene, 2002). This implementation would require only slight modifications to existing spreading activation models, since access to the lexicon would still occur through feedforward transmission of information from concepts to the lexicon. Importantly, however, in a naming task access to the lexicon will be faster because top-down influences will favor the lexicalization process due to the enhanced level of activation of the lexical system and/or the connections feeding into it. Hence, the observed pP2 deflections can be considered as the index of an interaction between the proactive top-down mechanism induced by task intention and the level of activation of lexical representations (see Fig 7A). In contrast, in the categorization task there is no need for top-down enhancements of the lexico-semantic pathway and the modulation of the pP2 will be absent here. Nevertheless, given the nature of spreading activation, eventually the activated conceptual system will pass on some information to the corresponding lexical items, producing a frequency effect. In this situation, the onset of lexical access will take place later in time (quantitative difference) and in isolation from any intentionally driven top-down processes (qualitative difference), which may be expressed by the N400 modulation for word frequency as we observed in the categorization experiment (see Fig. 7B).

A second possibility (though not mutually exclusive with the previous one) is that the intention-driven mechanism directly activates plausible word candidates by making wellestimated guesses based on contextual cues (e.g., Bar, 2003; Bar et al., 2006; Delong et al., 2005; Schiller, Horemans, Ganushchak, \& Koester, 2009). An especially elegant proposal for recognizing objects (and without the presence of a specific context) claims that the brain uses the low-spatial frequency of perceived objects to predict what they might represent prior to the completion of the sensory-driven recognition (Bar, 2003; Bar et al., 2006). A similar top-down mechanism could be at work during object naming, but instead of (or alongside with) anticipating potential object candidates, the top-down signals might preactivate potential word candidates. This may work in the following manner: A partially analyzed version of the visual input (low spatial frequencies) is rapidly transmitted to the prefrontal cortex (PFC) where expectations about the picture semantics are build up (Bar, 2003). These expectations are then used to pre-activate plausible lexical representations prior to the feedforward flow coming from the conceptual system. In this slightly adapted (and simplified) version of Bar's object prediction model (2003) eventual selection of the word one intends to utter will occur when the feedforward activation from the semantic system corresponds to and maps onto the guesses instantiated by the top-down projections. In this context, the pP2 may be indexing either the activation of the anticipated words made by the proactive top-down signals themselves, or the match between the pre-activated words 
and the information coming from the semantic system (see Fig. 7C; see for similar claims regarding perceptual features Federmeier et al., 2007). As in the previous framework, during the categorization task there is no need for the top-down processes to facilitate lexical items (but it will likely project to the object representation system; Bar, 2003). Consequently, lexical access will be achieved via only one source, feedforward spreading activation from concepts to words, without having the benefit from proactive facilitation. The N400 frequency effect observed for categorization may have appeared as a consequence of the lexical knowledge which eventually gets triggered by the activated semantic representations in this non-verbal conceptual task (see Fig. 7D).

Although our current data do not allow us to distinguish between the two tentative frameworks we described here (as well as similar top-down (attentional) mechanisms with slightly different properties are thinkable; e.g., Garagnani, Wennekers, \& Pulvermüller, 2008), they do provide convincing evidence that intention to speak is the driving force behind speeded word retrieval. This finding accentuates the need to explore the nature of proactive facilitation in future work - a topic which to date has received little to no attention in the language production literature.

\section{Conclusion}

The present set of results offer evidence regarding the role of proactive top-down processes for accessing words in speech production. By contrasting the ERP effects of word frequency in a task where participants had naming intention with a task were there was no naming intention, we have been able to demonstrate that the conscious intention to speak proactively facilitates the initial activation of words related to perceived objects. We concluded that no current speech production model was capable of accommodating all the findings and argued that spreading activation models of lexical access need to be complemented with a top-down mechanism able to proactively tune the lexical system. Still many important questions remain and novel ones surfaced: Can the proactive top-down mechanism also ignore distractor objects we do not intend to name while verbalizing other objects? Is the overt behavior of speech a necessary requisite to entail the top-down processes we observed or is the intention to retrieve lexical knowledge sufficient? How exactly do the biasing signals affect the lexicon? Can other components related to speech production also be proactively facilitated? The present study offers both the theoretical framework and the methodological tools to approach these and other challenging questions regarding the brain dynamics underlying the production of speech.

\section{Acknowledgments}

We are grateful to E. Runnqvist for revising and commenting previous versions of the manuscript and to C. Yum for her help in collecting the data of Experiment 1. K.S. was supported by a pre-doctoral fellowship from the Spanish Government (FPU - 2007-2011). P.H. was supported by grant number HD25889. A.C. was supported by a Grant from the Spanish Government (PSI2008-01191) and the Project Consolider-Ingenio 2010 (CSD 2007)-00012).

\section{References}

Allopenna PD, Magnuson JS, Tanenhaus MK. Tracking the time course of spoken word recognition using eye movements: Evidence for continuous mapping models. Journal of Memory and Language. 1998; 38:419-439.

Almeida J, Knobel M, Finkbeiner M, Caramazza A. The locus of the frequency effect in picture naming: When recognizing is not enough. Psychonomic Bulletin \& Review. 2007; 14:1177-1182. [PubMed: 18229493] 
Anllo-Vento L, Hillyard SA. Selective attention to the color and direction of moving stimuli: Electrophysiological correlates of hierarchical feature selection. Perception \& Psychophysics. 1996; 58:191-206. [PubMed: 8838164]

Bar M. A cortical mechanism for triggering top-down facilitation in visual object recognition. Journal of Cognitive Neuroscience. 2003; 15:600-609. [PubMed: 12803970]

Bar M, Kassam KS, Ghuman AS, Boshyan J, Schmidt AM, Dale AM, et al. Top-down facilitation of visual recognition. Proceedings of the National Academy of Science USA. 2006; 103:449-454.

Barrett SE, Rugg MD. Event-related potentials and the semantic matching of faces. Neuropsychologia. 1989; 27:913-922. [PubMed: 2771030]

Bates E, D’Amico S, Jacobsen T, Szekely A, Andonova E, Devescovi A, et al. Timed picture naming in seven languages. Psychonomic Bulletin \& Review. 2003; 10:344-380. [PubMed: 12921412]

Belke E, Humphreys GW, Watson DG, Meyer AS, Telling AL. Top-down effects of semantic knowledge in visual search are modulated by cognitive but not perceptual load. Perception \& Psychophysics. 2008; 70:1444-1458. [PubMed: 19064489]

Besson M, Kutas M, Van Petten C. An event-related potential analysis of semantic congruity and repetition effects in sentences. Journal of Cognitive Neuroscience. 1992; 4:132-149. [PubMed: 23967889]

Bles M, Jansma BM. Phonological processing of ignored distractor pictures, an fMRI investigation. BMC Neuroscience. 2008; 9:20. [PubMed: 18267005]

Bloem I, La Heij W. Semantic facilitation and semantic interference in word translation: Implications for models of lexical access in language production. Journal of Memory and Language. 2003; 48:468-488.

Bloem I, van der Boogaard S, La Heij W. Semantic facilitation and semantic interference in language production: Further evidence for the conceptual selection model of lexical access. Journal of Memory and Language. 2004; 51:307-323.

Brown AS. Inhibition in cued retrieval. Journal of Experimental Psychology: Human Learning and Memory. 1981; 7:204-215.

Caramazza A. How many levels of processing are there in lexical access? Cognitive Neuropsychology. 1997; 14:177-208.

Caramazza A, Costa A, Miozzo M, Bi Y. The specific-word frequency effect: Implications for the representation of homophones. Journal of Experimental Psychology: Learning, Memory and Cognition. 2001; 27:1430-1450.

Carreiras M, Vergara M, Barber H. Early ERP effects of syllabic processing during visual word recognition. Journal of Cognitive Neuroscience. 2005; 17:1803-1817. [PubMed: 16269115]

Christoffels IK, Firk C, Schiller NO. Bilingual language control: An event-related brain potential study. Brain Research. 2007; 1147:192-208. [PubMed: 17391649]

Cohen JD, Dunbar K, McClelland JL. On the control of automatic processes: A parallel distributed processing account of the Stroop effect. Psychological Review. 1990; 97:332-361. [PubMed: 2200075]

Collins AM, Loftus EF. A spreading activation theory of semantic processing. Psychological Review. 1975; 82:407-428.

Corbetta M, Miezin FM, Dobmeyer S, Shulman GL, Petersen SE. Attentional modulation of neural processing of shape, color, and velocity in humans. Science. 1990; 248:1556-1559. [PubMed: 2360050]

Costa A, Caramazza A. The production of noun phrases in English and Spanish: Implications for the scope of phonological encoding in speech production. Journal of Memory and Language. 2002; 46:178-198.

Costa A, Caramazza A, Sebastian-Galles N. The cognate facilitation effect: Implications for models of lexical access. Journal of Experimental Psychology: Learning Memory and Cognition. 2000; 26:1283-1296.

Costa A, Santesteban M, Cano A. On the facilitatory effects of cognate words in bilingual speech production. Brain and Language. 2005; 94:94-103. [PubMed: 15896387] 
Costa A, Strijkers K, Martin C, Thierry G. The time course of word retrieval revealed by event-related brain potentials during overt speech. Proceedings of the National Academy of Science USA. 2009; 106:21442-21446.

Cutting JC, Ferreira VS. Semantic and phonological information flow in the production lexicon. Journal of Experimental Psychology: Learning, Memory, and Cognition. 1999; 25:318-344.

Dahan D, Tanenhaus M. Looking at the rope when looking for the snake: Conceptually mediated eye movements during spokenword recognition. Psychonomic Bulletin \& Review. 2005; 12:453-459. [PubMed: 16235628]

Damian MF, Bowers JS. Locus of semantic interference in picture - Word interference tasks. Psychonomic Bulletin \& Review. 2003; 10:111-117. [PubMed: 12747497]

Dell GS. A spreading-activation theory of retrieval in sentence production. Psychological Review. 1986; 93:283-321. [PubMed: 3749399]

Dell GS, O'Seaghdha PG. Stages of lexical access in language production. Cognition. 1992; 42:287314. [PubMed: 1582160]

DeLong KA, Urbach TP, Kutas M. Probabilistic word preactivation during language comprehension inferred from electrical brain activity. Nature Neuroscience. 2005; 8:1117-1121.

Dent K, Johnston RA, Humphreys GW. Age of acquisition and word frequency effects in picture naming: A dual-task investigation. Journal of Experimental Psychology: Learning, Memory, and Cognition. 2008; 34:282-301.

Desimone R, Duncan J. Neural mechanisms of selective visual attention. Annual Review of Neuroscience. 1995; 18:193-222.

Dunn BR, Dunn DA, Languis M, Andrews D. The relation of ERP components to complex memory processing. Brain and Cognition. 1998; 36(3):355-376. [PubMed: 9647684]

Eddy M, Schmid A, Holcomb P. Masked repetition priming and event-related brain potentials: A new approach for tracking the time-course of object perception. Psychophysiology. 2006; 43:564-568. [PubMed: 17076812]

Engel AK, Fries P, Singer W. Dynamic predictions: Oscillations and synchrony in top-down processing. Nature Reviews Neuroscience. 2001; 2:704-716.

Federmeier KD. Thinking ahead: The role and roots of prediction in language comprehension. Psychophysiology. 2007; 44:491-505. [PubMed: 17521377]

Federmeier KD, Kutas M. A rose by any other name: Longterm memory structure and sentence processing. Journal of Memory and Language. 1999; 41:469-495.

Federmeier KD, Kutas M. Picture the difference: Electrophysiological investigations of picture processing in the two cerebral hemispheres. Neuropsychologia. 2002; 40:730-747. [PubMed: 11900725]

Federmeier KD, Kutas M. Aging in context: Age-related changes in context use during language comprehension. Psychophysiology. 2005; 42:133-141. [PubMed: 15787850]

Federmeier KD, Mai H, Kutas M. Both sides get the point: Hemispheric sensitivities to sentential constraint. Memory \& Cognition. 2005; 33:871-886. [PubMed: 16383175]

Federmeier KD, Wlotko E, De Ochoa-Dewald E, Kutas M. Multiple effects of sentential constraint on word processing. Brain Research. 2007; 1146:75-84. [PubMed: 16901469]

Garagnani M, Wennekers T, Pulvermüller FA. Neuroanatomically-grounded Hebbian learning model of attentionlanguage interactions in the human brain. European Journal of Neuroscience. 2008; 27:492-513. [PubMed: 18215243]

Gilbert CD, Sigman M. Brain states: Top-down influences in sensory processing. Neuron. 2007; 54:677-696. [PubMed: 17553419]

Glaser WR, Glaser MO. Context effects on Stroop-like word and picture processing. Journal of Experimental Psychology: General. 1989; 118:13-42. [PubMed: 2522504]

Grainger J, Holcomb PJ. Watching the word go by: On the time course of component processes in visual word recognition. Language and Linguistic Compass. 2009; 3:128-156.

Graves WW, Grabowski TJ, Mehta S, Gordon JK. A neural signature of phonological access: Distinguishing the effects of word frequency from familiarity and length in overt picture naming. Journal of Cognitive Neuroscience. 2007; 19:617-631. [PubMed: 17381253] 
Griffin, ZM. Why look? Reasons for eye movements related to language production. In: Henderson, JM.; Ferreira, F., editors. The interface of language, vision, and action: What we can learn from free-viewing eye tracking. New York: Psychology Press; 2004. p. 213-247.

Griffin ZM, Bock K. Constraint, word frequency, and the relationship between lexical processing levels in spoken word production. Journal of Memory and Language. 1998; 38:313-338.

Griffin ZM, Bock K. What the eyes say about speaking. Psychological Science. 2000; 11:274-279. [PubMed: 11273384]

Grill-Spector K, Henson R, Martin A. Repetition and the brain: Neural models of stimulus-specific effects. Trends in Cognitive Science. 2006; 10:14-23.

Grill-Spector K, Kanwisher N. Visual recognition: As soon as you know it is there, you know what it is. Psychological Science. 2005; 16:152-160. [PubMed: 15686582]

Guthrie D, Buchwald JS. Significance testing of difference potentials. Psychophysiology. 1991; 28:240-244. [PubMed: 1946890]

Hagoort P. The fractionation of spoken language understanding by measuring electrical and magnetic brain signals. Philosophical Transactions of the Royal Society of London B: Biological Sciences. 2008; 363:1055-1069.

Halgren E, Dhond RP, Christensen N, Van Petten C, Marinkovic K, Lewine JD, et al. N400-like magnetoencephalography responses modulated by semantic context, word frequency, and lexical class in sentences. Neuroimage. 2002; 17:1101-1116. [PubMed: 12414253]

Hauk O, Patterson K, Woollams A, Cooper-Pey E, Pulvermüller F, Rogers TT. How the camel lost its hump: The impact of object typicality on event-related potential signals in object decision. Journal of Cognitive Neuroscience. 2007; 19:1338-1353. [PubMed: 17651007]

Hauk O, Pulvermuller F. Effects of word length and frequency on the human event-related potential. Clinical Neurophysiology. 2004; 115:1090-1103. [PubMed: 15066535]

Henson RNA, Rylands A, Ross E, Vuilleumeir P, Rugg MD. The effect of repetition lag on electrophysiological and haemodynamic correlates of visual object priming. Neuroimage. 2004; 21:1674-1689. [PubMed: 15050590]

Hillyard SA, Munte TF. Selective attention to color and location: An analysis with event-related brain potentials. Perception \& Psychophysics. 1984; 36:185-198. [PubMed: 6514528]

Hillyard SA, Vogel EK, Luck SJ. Sensory gain control (amplification) as a mechanism of selective attention: Electrophysiological and neuroimaging evidence. Philosophical Transactions of the Royal Society Biological Sciences. 1998; 353:1257-1267. [PubMed: 9770220]

Holcomb PJ. Semantic priming and stimulus degradation: Implications for the role of the N400 in language processing. Psychophysiology. 1993; 30:47-61. [PubMed: 8416062]

Holcomb PJ, Grainger J. The time course of masked repetition priming: An event-related brain potential investigation. Journal of Cognitive Neuroscience. 2006; 18:1631-1643. [PubMed: 17014368]

Holcomb PJ, McPherson WB. Event-related brain potentials reflect semantic priming in an object decision task. Brain and Cognition. 1994; 24:259-276. [PubMed: 8185897]

Howard D, Nickels L, Coltheart M, Cole-Virtue J. Cumulative semantic inhibition in picture naming: Experimental and computational studies. Cognition. 2006; 100:464-482. [PubMed: 16413014]

Huettig F, McQueen JM. The tug of war between phonological, semantic, and shape information in language-mediated visual search. Journal of Memory and Language. 2007; 54:460-482.

Humphreys GW, Riddoch MJ, Price CJ. Top-down processes in object identification: Evidence from experimental psychology, neuropsychology, and functional anatomy. Philosophical Transactions: Biological Sciences. 1997; 352:1275-1282. [PubMed: 9304694]

Indefrey P, Levelt WJM. The spatial and temporal signatures of word production components. Cognition. 2004; 92:101-144. [PubMed: 15037128]

Jescheniak JD, Levelt WJM. Word frequency effects in speech production: Retrieval of syntactic information and of phonological form. Journal of Experimental Psychology: Learning, Memory, and Cognition. 1994; 20:824-843.

Jescheniak JD, Oppermann F, Hantsch A, Wagner V, Madebach A, Schriefers H. Do perceived context pictures automatically activate their phonological code? Experimental Psychology. 2009; 56:5665. [PubMed: 19261579] 
Jescheniak JD, Schriefers H, Garrett MF, Friederici AD. Exploring the activation of semantic and phonological codes during speech planning with event-related brain potentials. Journal of Cognitive Neuroscience. 2002; 94:94-103.

Kanwisher N, Wojciulik E. Visual attention: Insights from brain imaging. Nature Reviews Neuroscience. 2000; 1:91-100.

Kastner S, Pinsk M, De Weerd P, Desimone R, Ungerleider L. Increased activity in human visual cortex during directed attention in the absence of visual stimulation. Neuron. 1999; 22:751-761. [PubMed: 10230795]

Kastner S, Ungerleider LG. Mechanisms of visual attention in the human cortex. Annual Review of Neuroscience. 2000; 23:315-341.

Kirchner H, Thorpe SJ. Ultra-rapid object detection with saccadic eye movements: Visual processing revisited. Vision Research. 2006; 46:1762-1776. [PubMed: 16289663]

Kittredge AK, Dell GS, Verkuilen J, Schwartz MF. Where is the effect of frequency in word production? Insights from aphasic picture-naming errors. Cognitive Neuropsychology. 2007; 1:130 .

Knobel M, Finkbeiner M, Caramazza A. The many places of frequency: Evidence for a novel locus of the lexical frequency effect in word production. Cognitive Neuropsychology. 2008; 25:256-286. [PubMed: 18568814]

Koester D, Schiller N. Morphological priming in overt language production: Electrophysiological evidence from Dutch. NeuroImage. 2008; 42:1622-1630. [PubMed: 18674626]

Kroll JF, Potter MC. Recognizing words, pictures, and concepts: A comparison of lexical, object, and reality decisions. Journal of Verbal Learning and Verbal Behaviour. 1984; 23:39-66.

Kutas M. In the company of other words: Electrophysiological evidence for single-word and sentence context effects. Language and Cognitive Processes. 1993; 8:533-572.

Kutas M, Federmeier KD. Electrophysiology reveals semantic memory use in language comprehension. Trends in Cognitive Sciences. 2000; 4:463-470. [PubMed: 11115760]

Kutas M, Hillyard SA. Reading senseless sentences: Brain potentials reflect semantic incongruity. Science. 1980; 207:203-205. [PubMed: 7350657]

Lau EF, Phillips C, Poeppel D. A cortical network for semantics: [de]constructing the N400. Nature Reviews Neuroscience. 2008; 9:920-933.

Lee CY, Tsai JL, Chan WH, Hsu CH, Hung DL, Tzeng OJ. Temporal dynamics of the consistency effect in reading Chinese: An event-related potentials study. Neuroreport. 2007; 18(2):147-151. [PubMed: 17301680]

Levelt, WJM. Speaking: From intention to articulation. MA: The MIT Press; 1989.

Levelt WJM, Roelofs A, Meyer AS. A theory of lexical access in speech production. Behavioural Brain Sciences. 1999; 22:1-75.

Levelt WJM, Schriefers H, Vorberg D, Meyer AS, Pechmann T, Havinga J. The time course of lexical access in speech production: A study of picture naming. Psychological Review. 1991; 98:122-142.

Liu H, Agam Y, Madsen JR, Kreiman G. Timing, timing, timing: Fast decoding of object information from intracranial field potentials in human visual cortex. Neuron. 2009; 62:281-290. [PubMed: 19409272]

Luck SJ, Chelazzi L, Hillyard SA, Desimone R. Neural mechanisms of spatial selective attention in areas V1, V2, and V4 of macaque visual cortex. Journal of Neurophysiology. 1997; 77:24-42. [PubMed: 9120566]

Luck SJ, Hillyard SA. Electrophysiological correlates of feature analysis during visual search. Psychophysiology. 1994; 31:291-308. [PubMed: 8008793]

Maess B, Friederici AD, Damian M, Meyer AS, Levelt WJM. Semantic category interference in overt picture naming: An MEG study. Journal of Cognitive Neuroscience. 2002; 14:455-462. [PubMed: 11970804]

Mangun, GR.; Hillyard, SA. Mechanisms and models of selective attention. In: Rugg, MD.; Coles, MGH., editors. Electrophysiology of mind. Oxford: Oxford University Press; 1995. p. 40-85.

Meyer AS, Belke E, Telling AL, Humphreys GW. Early activation of object names in visual search. Psychonomic Bulletin and Review. 2007; 14:710-716. [PubMed: 17972738] 
Meyer AS, Damian MF. Activation of distractor names in the picture-picture interference paradigm. Memory and Cognition. 2007; 35:494-503. [PubMed: 17691148]

Meyer AS, Sleiderink AM, Levelt WJM. Viewing and naming objects: Eye movements during noun phrase production. Cognition. 1998; 66:25-33.

Morgan JL, Meyer AS. Processing of extrafoveal objects during multiple object naming. Journal of Experimental Psychology: Language, Memory, \& Cognition. 2005; 31:428-442.

Morrison CM, Ellis AW, Quinlan PT. Age of acquisition, not word frequency, affects object naming, not object recognition. Memory \& Cognition. 1992; 20:705-714. [PubMed: 1435273]

Morsella E, Miozzo M. Evidence for a cascade model of lexical access in speech production. Journal of Experimental Psychology: Learning, Memory and Cognition. 2002; 28:555-563.

Naccache L, Blandin E, Dehaene S. Unconscious masked priming depends on temporal attention. Psychological Science. 2002; 13:416-424. [PubMed: 12219807]

Navarrete E, Basagni B, Alario XF, Costa A. Does word frequency affect lexical selection in speech production? The Quarterly Journal of Experimental Psychology. 2006; 10:1681-1690. [PubMed: 16945853]

Navarrete E, Costa A. Phonological activation of ignored pictures: Further evidence for a cascade model of lexical access. Journal of Memory and Language. 2005; 53:359-377.

Navarrete E, Mahon BZ, Caramazza A. The cumulative semantic cost does not reflect lexical selection by competition. Acta Psychologica. 2010; 134:279-289. [PubMed: 20347062]

Neely JH. Semantic priming and retrieval from lexieal memory: Roles of inhibitionless spreading activation and limited capacity attention. Journal of Experimental Psychology: General. 1977; 106:226-254.

O'Craven K, Kanwisher N. Mental imagery of faces and places activates corresponding stimulusspecific brain regions. Journal of Cognitive Neuroscience. 2000; 12:1013-1023. [PubMed: 11177421]

O'Hare AJ, Dien J, Waterson LD, Savage CR. Activation of the posterior cingulate by semantic priming: A Co-registered ERP/ fMRI study. Brain Research. 2008; 1189:97-114. [PubMed: 18061152]

Oppenheim GM, Dell GS, Schwartz MF. Cumulative semantic interference as learning. Brain and Language. 2007; 103:175-176.

Oppenheim GM, Dell GS, Schwartz MF. The dark side of incremental learning: A model of cumulative semantic interference during lexical access in speech production. Cognition. 2010; 114:227-252. [PubMed: 19854436]

Oppermann F, Jescheniak JD, Schriefers H. Conceptual coherence affects phonological activation of context objects during object naming. Journal of Experimental Psychology: Learning, Memory and Cognition. 2008; 34:587-601.

Oppermann F, Jescheniak JD, Schriefers H, Gorges F. Semantic relatedness among objects promotes the activation of multiple phonological codes during object naming. The Quarterly Journal of Experimental Psychology. 2010; 63:356-370. [PubMed: 19557668]

Peelen MV, Fei-Fei L, Kastner S. Neural mechanisms of rapid natural scene categorization inhuman visual cortex. Nature. 2009; 460:94-97. [PubMed: 19506558]

Peterson RR, Savoy P. Lexical selection and phonological encoding during language production: Evidence for cascaded processing. Journal of Experimental Psychology: Learning, Memory, and Cognition. 1998; 24:539-557.

Posner MI, Dehaene S. Attentional networks. Trends in Neuroscience. 1994; 17:75-79.

Pulvermüller F, Shtyrov Y, Hauk O. Understanding in an instant: Neurophysiological evidence for mechanistic language circuits in the brain. Brain and Language. 2009; 110:81-94. [PubMed: 19664815]

Pylkkanen L, Marantz A. Tracking the time course of word recognition with MEG. Trends in Cognitive Sciences. 2003; 7:187-189. [PubMed: 12757816]

Roelofs A. A spreading-activation theory of lemma retrieval in speaking. Cognition. 1992; 42:107142. [PubMed: 1582154] 
Roelofs A. Goal-referenced selection of verbal action: Modelling attentional control in the Stroop task. Psychological Review. 2003; 110:88-125. [PubMed: 12529058]

Roelofs A. Context effects of pictures and words in naming objects, reading words, and generating simple phrases. Quarterly Journal of Experimental Psychology. 2006; 59:1764-1784.

Roelofs A. Attention to spoken word planning: Chronometric and neuroimaging evidence. Language and Linguistic Compass. 2008; 2:389-405.

Rosch, E. Principles of categorization. In: Rosch, BE.; Lloyd, editors. Cognition and categorization. Hillsdale, NJ: Erlbaum; 1978.

Rugg MD. Event-related brain potentials dissociate repetition effects of high- and low-frequency words. Memory \& Cognition. 1990; 18:367-379. [PubMed: 2381316]

Rugg, MD.; Doyle, MC. Event-related potentials and stimulus repetition in direct and indirect tests of memory. In: Heinze, H-J.; Munte, TF.; Mangun, GR., editors. Cognitive electrophysiology. Boston: Birkhauser; 1994. p. 124-148.

Sahin N, Pinker S, Cash S, Schomer D, Halgren E. Sequential processing of lexical, grammatical, and phonological information within Broca's area. Science. 2009; 326:445-449. [PubMed: 19833971]

Schendan HE, Ganis G, Kutas M. Neurophysiological evidence for visual perceptual categorization of words and faces within 150 ms. Psychophysiology. 1998; 35:240-251. [PubMed: 9564744]

Schendan HE, Kutas M. Time course of processes and representations supporting visual object identification and memory. Journal of Cognitive Neuroscience. 2003; 15:111-135. [PubMed: 12590847]

Schendan HE, Kutas M. Neuropsychological evidence for the time course of activation of global shape, part, and local contour representations during visual object categorization and memory. Journal of Cognitive Neuroscience. 2007; 19:734-749. [PubMed: 17488201]

Schiller NO, Horemans I, Ganushchak L, Koester D. Eventrelated potentials during the monitoring of speech errors. NeuroImage. 2009; 44:520-530. [PubMed: 18930155]

Schriefers H, Meyer AS, Levelt WJM. Exploring the time course of lexical access in language production: Picture-word interference studies. Journal of Memory and Language. 1990; 29:86102.

Sitnikova T, West WC, Kuperberg GR, Holcomb PJ. The neural organization of semantic memory: Electrophysiological activity suggests feature-based segregation. Biological Psychology. 2006; 71:326-340. [PubMed: 16129544]

Snodgrass JG, Vanderwart M. A standardized set of 260 pictures: Norm for name agreement, image agreement, familiarity, and visual complexity. Journal of Experimental Psychology: Human Learning and Memory. 1980; 6:174-215. [PubMed: 7373248]

Strijkers K, Costa A, Thierry G. Tracking lexical access in speech production: Electrophysiological correlates of word frequency and cognate effects. Cerebral Cortex. 2010; 20:912-928. [PubMed: 19679542]

Tanenhaus MK, Magnuson JS, Dahan D, Chambers CG. Eye movements and lexical access in spoken language comprehension: Evaluating a linking hypothesis between fixations and linguistic processing. Journal of Psycholinguistic Research. 2000; 29:557-580. [PubMed: 11196063]

ter Keurs M, Brown CM, Hagoort P, Stegeman DF. Electrophysiological manifestations of open- and closed-class words in patients with Broca's aphasia with agrammatic comprehension. An eventrelated brain potential study. Brain. 1999; 122:839-854. [PubMed: 10355670]

Thierry G, Cardebat D, Demonet JF. Electrophysiological comparison of grammatical processing and semantic processing of single spoken nouns. Cognitive Brain Research. 2003; 17:535-547. [PubMed: 14561443]

Thierry G, Martin CD, Downing P, Pegna AJ. Controlling for interstimulus perceptual variance abolishes N170 face selectivity. Nature Neuroscience. 2007; 10:505-511.

Thorpe S, Fize D, Marlot C. Speed of processing in the human visual system. Nature. 1996; 381:520522. [PubMed: 8632824]

Ullman S. Sequence seeking and counter streams: A computational model for bidirectional information flow in the visual cortex. Cerebral Cortex. 1995; 1:1-11. [PubMed: 7719126] 
Van Petten C. Words and sentences: Event-related brain potential measures. Psychophysiology. 1995; 32:511-525. [PubMed: 8524986]

Van Petten C, Kutas M. Interactions between sentence context and word frequency in event-related brain potentials. Memory \& Cognition. 1990; 18:380-393. [PubMed: 2381317]

Van Petten C, Kutas M. Influences of semantic and syntactic context on open and closed class words. Memory \& Cognition. 1991; 19:95-112. [PubMed: 2017035]

Van Petten C, Kutas M, Kluender R, Mitchiner M, McIsaac H. Fractionating the word repetition effect with event-related potentials. Journal of Cognitive Neuroscience. 1991; 3:131-150. [PubMed: 23972089]

Van Petten C, Senkfor AJ. Memory for words and novel visual patterns: Repetition, recognition, and encoding effects in the eventrelated brain potential. Psychophysiology. 1996; 33:491-506. [PubMed: 8854736]

VanRullen R, Thorpe SJ. Surfing a spike wave down the ventral stream. Vision Research. 2002; 42:2593-2615. [PubMed: 12446033]

Verhoef K, Roelofs A, Chwilla JC. Role of inhibition in language switching: Evidence from eventrelated brain potentials in overt picture naming. Cognition. 2009; 110:84-99. [PubMed: 19084830]

Wingfield A. Effects of frequency on identification and naming of objects. American Journal of Psychology. 1968; 81:226-234. [PubMed: 5747965]

Wlotko EW, Federmeier KD. Finding the right word: Hemispheric asymmetries in the use of sentence context information. Neuropsychologia. 2007; 45:3001-3014. [PubMed: 17659309] 


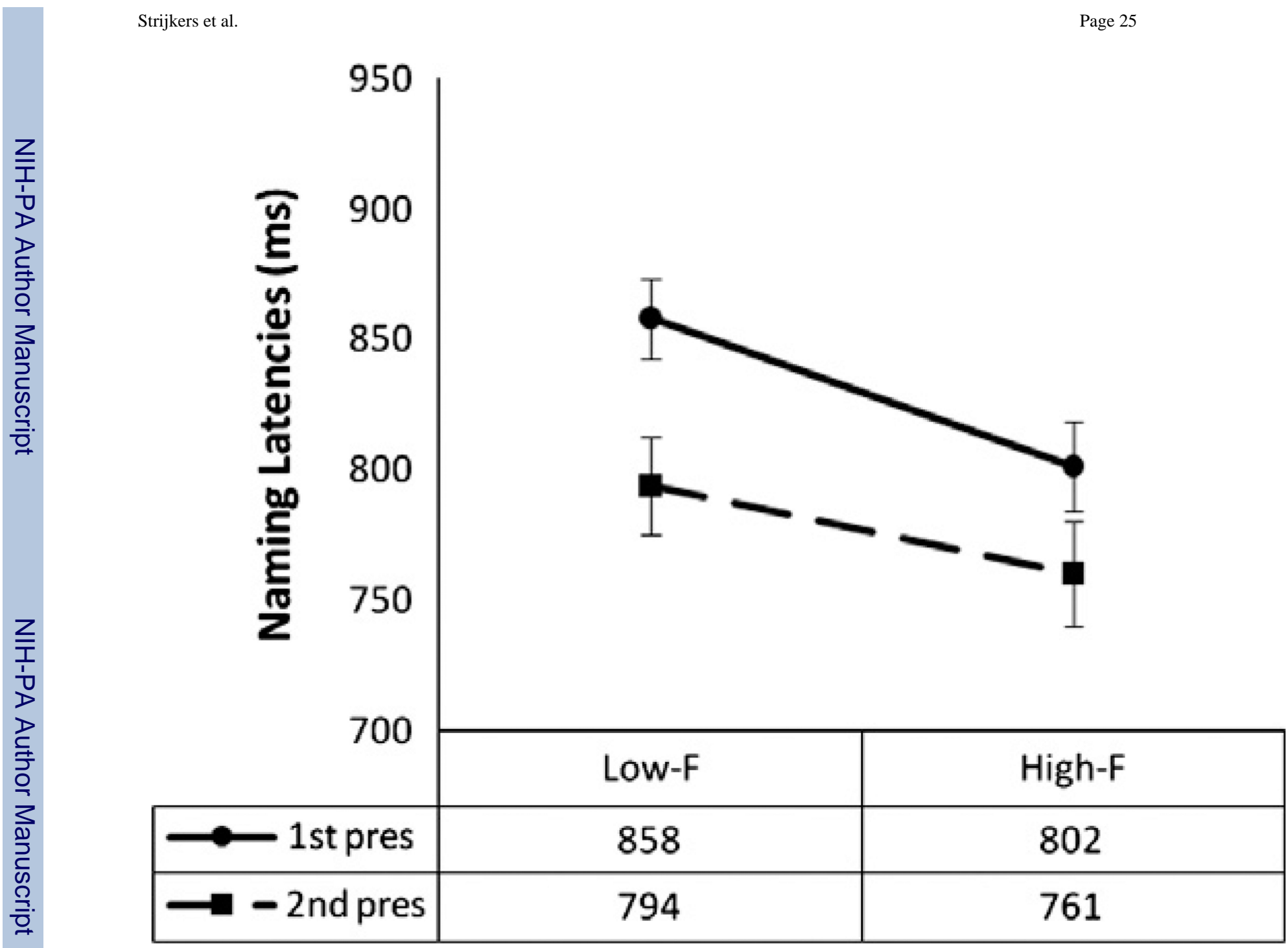

Fig. 1.

Naming latencies (in ms) of Experiment 1 for the repetition and frequency effects. 

(a)
(b)
Repetition Effect
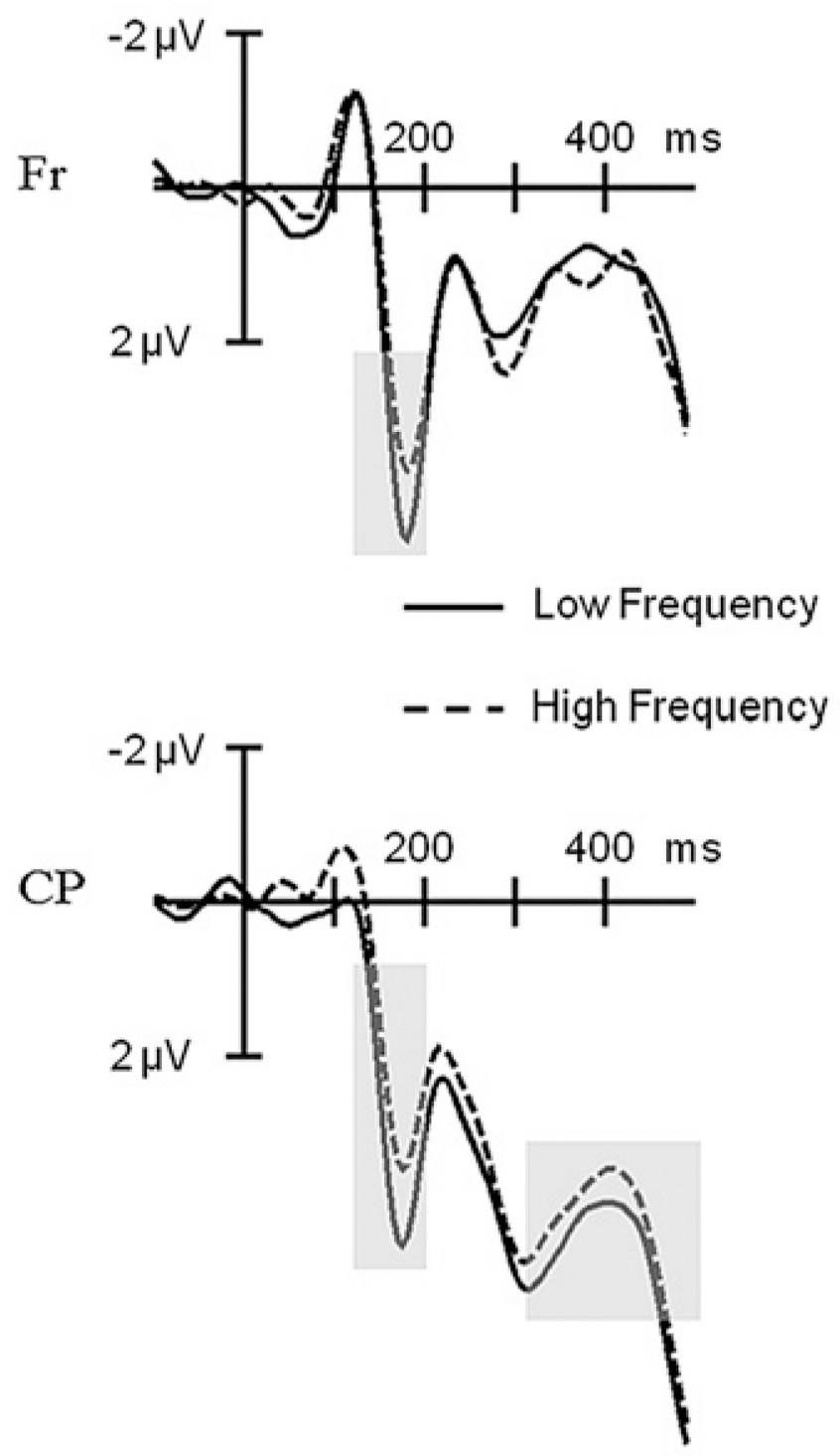

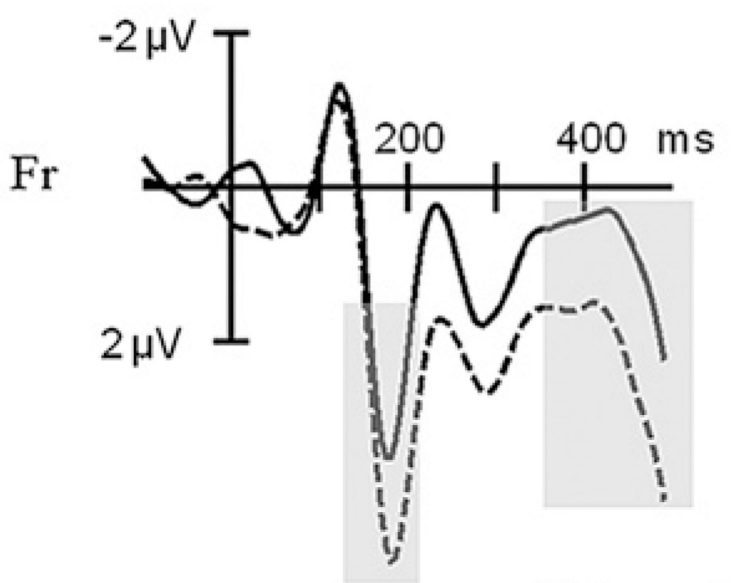

$1^{\text {st }}$ Presentation

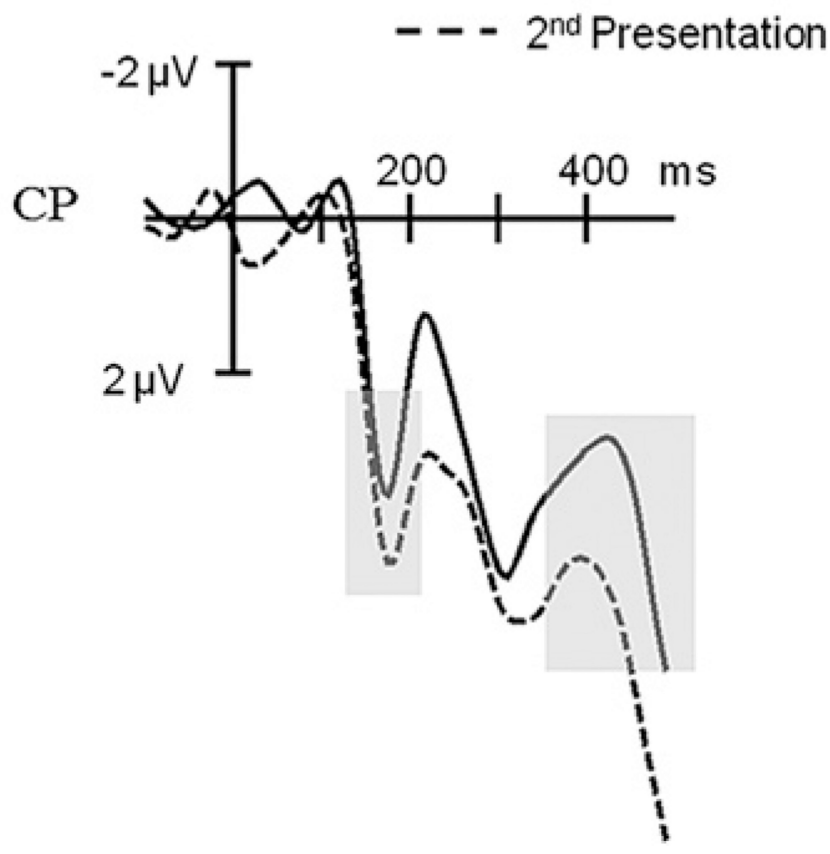

Fig. 2.

Event-related potential results of Experiment 1. (a) ERPs elicited by pictures with low compared to those with high frequency names at Frontal (Fr) and Centro-Parietal (CP) electrode clusters. Grayed areas show significant frequency effects at the P2 and N400. (b) ERPs elicited by the first compared to the second picture presentation at Frontal (Fr) and Centro-Parietal (CP) electrode clusters. Grayed areas show significant repetition effects at the $\mathrm{P} 2$ and $\mathrm{N} 400$. 

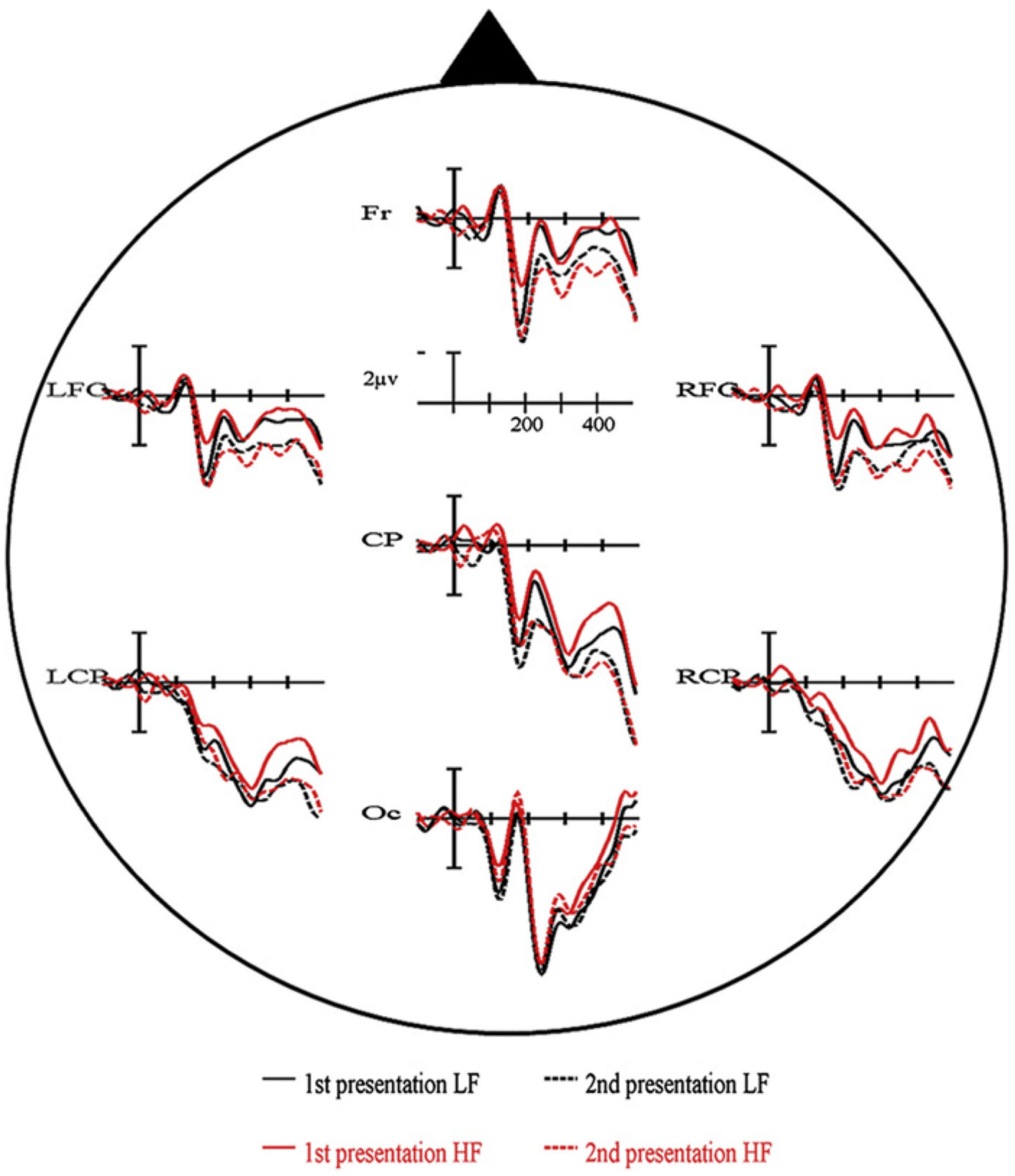

Fig. 3.

Event-related potential results of Experiment 1 for all conditions (1st presentation low frequency (LF), 2nd presentation low frequency (LF), 1st presentation high frequency (HF), 2nd presentation high frequency (HF)) at all seven electrode clusters. 


\section{Frequency Effect}

\section{$\underline{\text { Repetition Effect }}$}

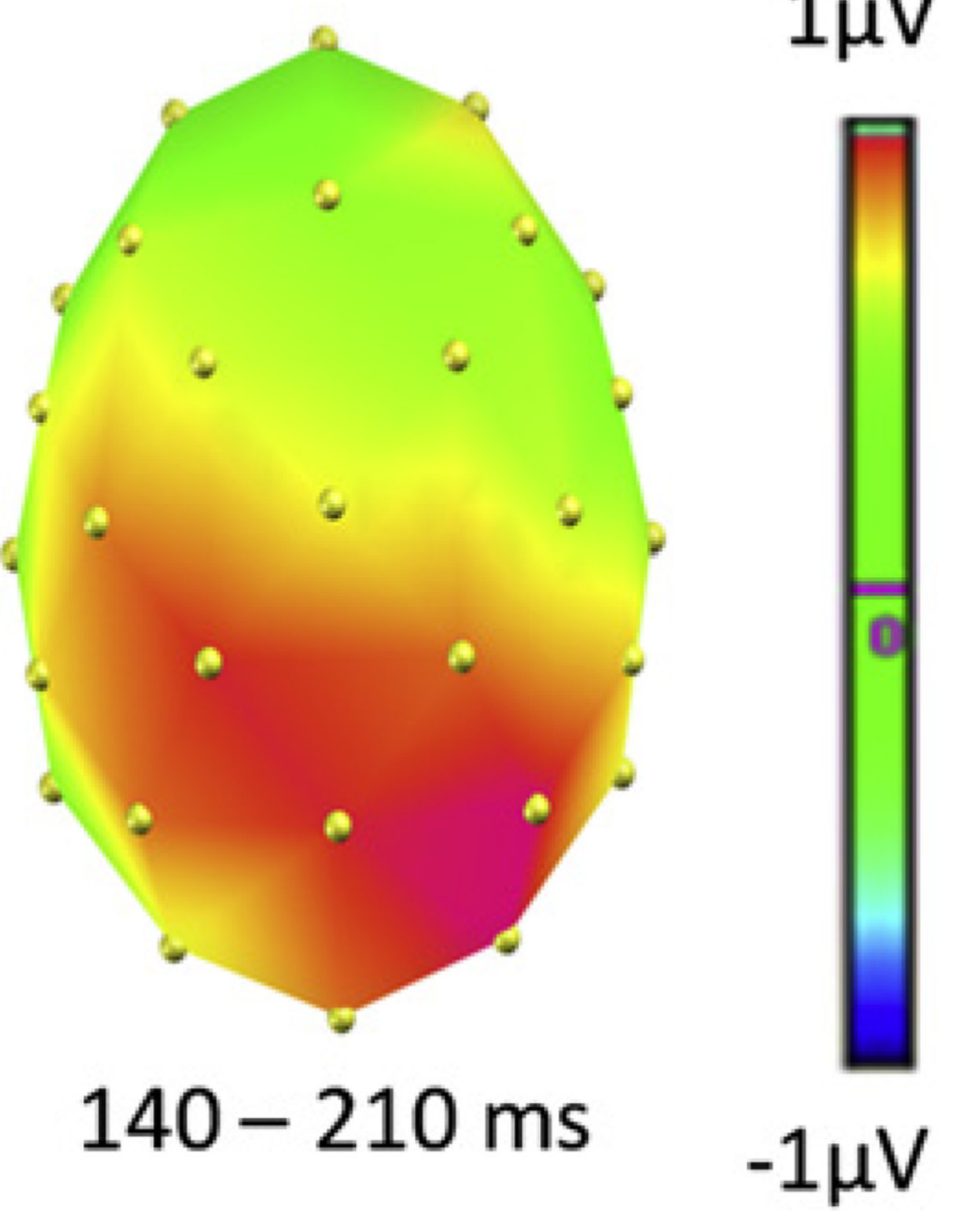

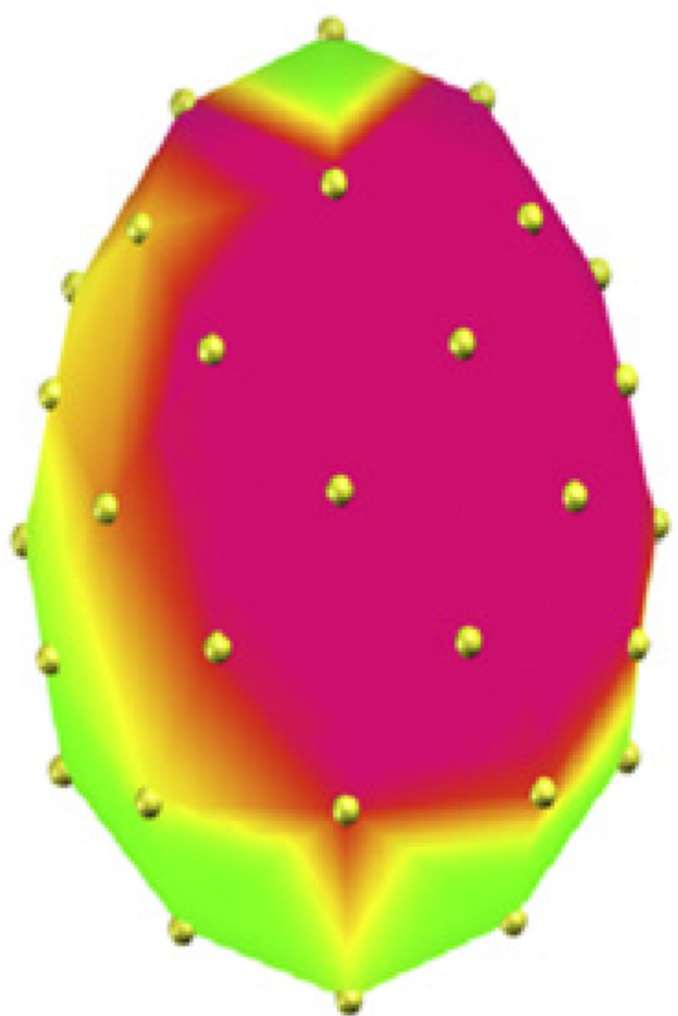

$140-210 \mathrm{~ms}$

Fig. 4.

Topographical distribution of the frequency (left) and repetition (right) effects for the P2 time window [140-210 ms] in Experiment 1. 
(a) Frequency Effect

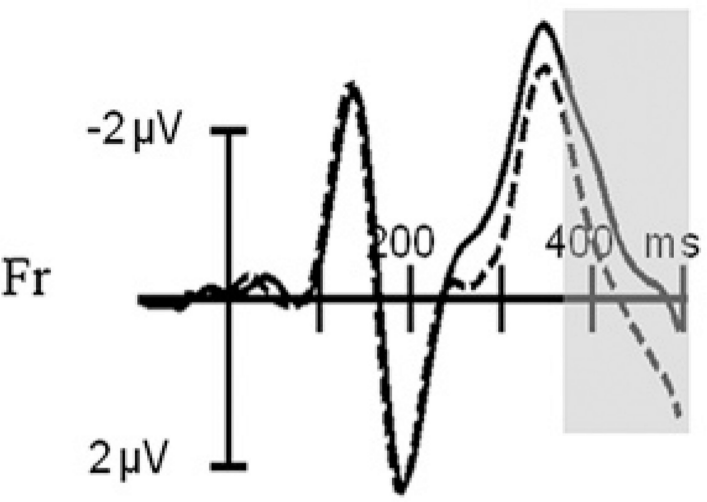

Low Frequency

- - - High Frequency

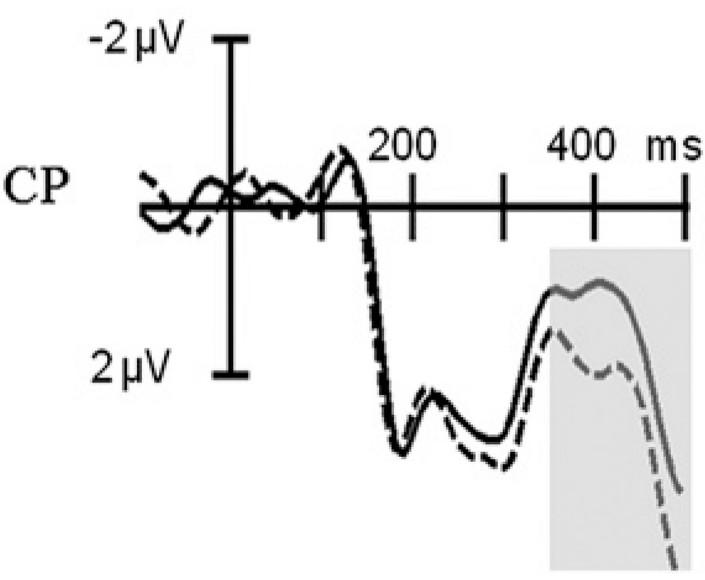

(b)

Repetition Effect

Fr

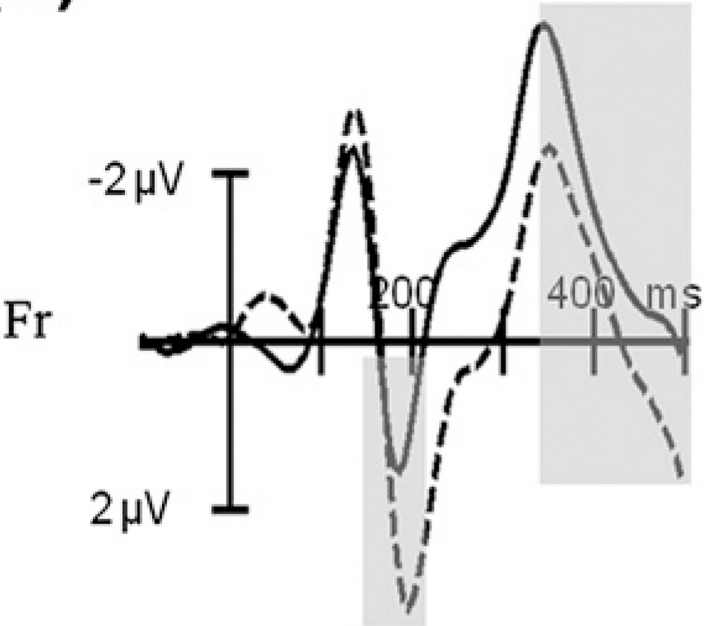

Fig. 5.

Event-related potential results of Experiment 2. (a) ERPs elicited by pictures with low compared to those with high frequency names at Frontal (Fr) and Centro-Parietal (CP) electrode clusters. Grayed areas show significant frequency effects at the N400. (b) ERPs elicited by the first compared to the second picture presentation at Frontal (Fr) and CentroParietal (CP) electrode clusters. Grayed areas show significant repetition effects at the P2 and N400. 


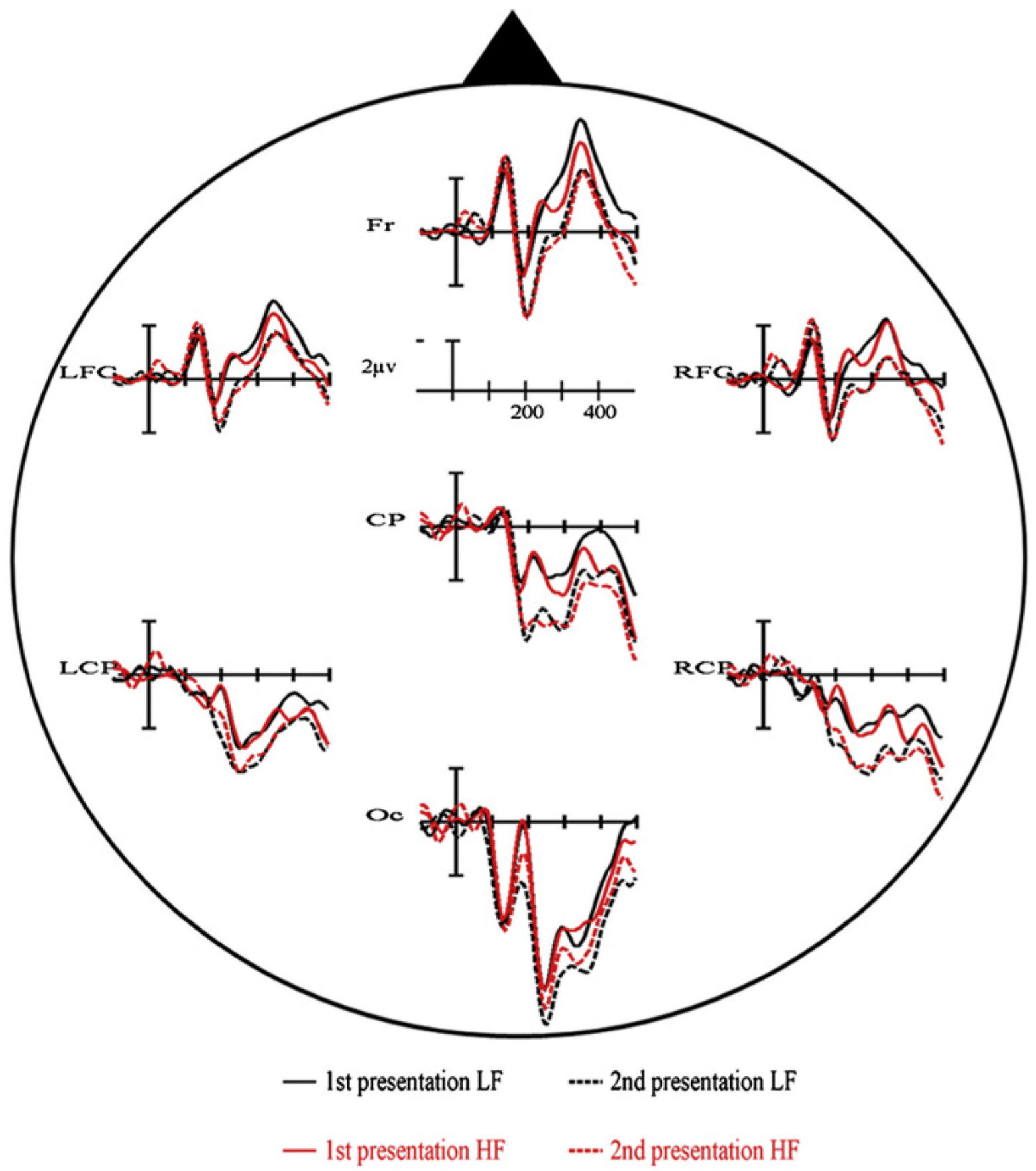

Fig. 6.

Event-related potential results of Experiment 2 for all conditions (1st presentation low frequency (LF), 2nd presentation low frequency (LF), 1st presentation high frequency (HF), 2nd presentation high frequency (HF)) at all seven electrode clusters. 


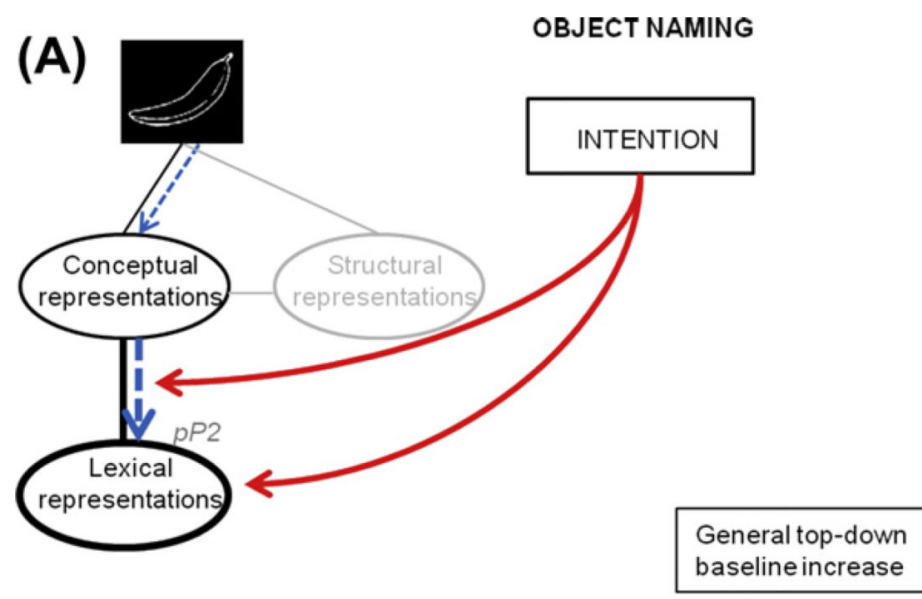

(B)

OBJECT CATEGORIZATION

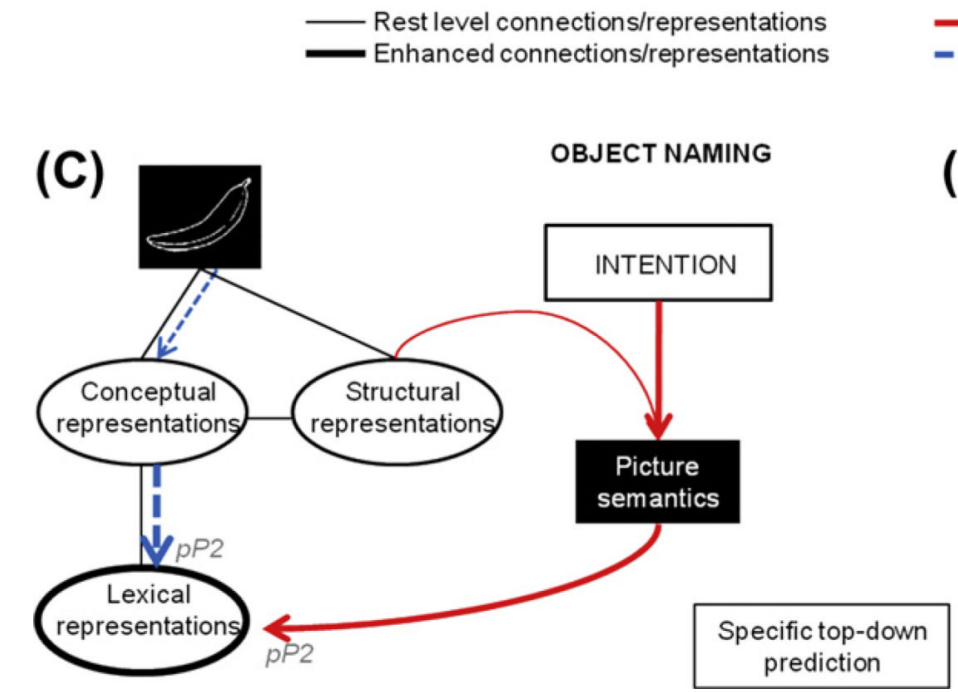

$\longrightarrow$ Proactive top-down activation
- Feedforward spreading activation

(D)

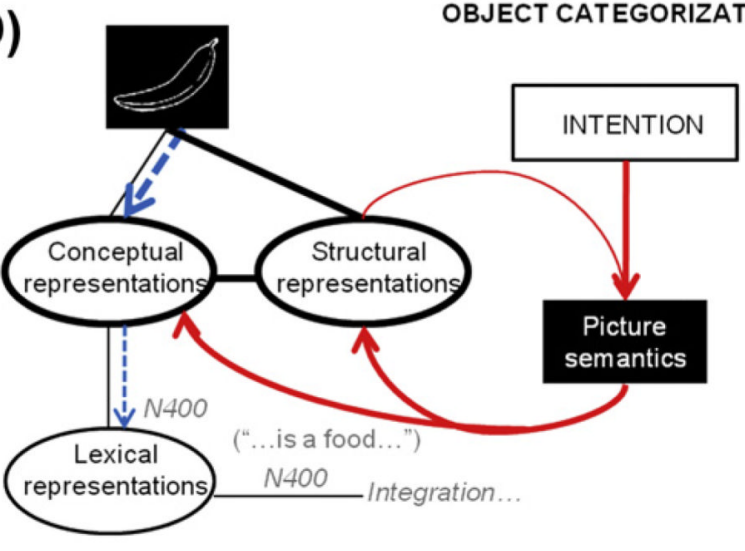

Fig. 7.

Schematic visualization of the potential top-down and lexical processes in object naming compared to object categorization and their subsequent electrophysiological expressions (these are not representative models, merely visual aids; more or less connections and "modules" are thinkable). A. Proactive top-down mechanism in terms of general baseline increase in object naming. The gray and in italic "pP2" indications refer to potential sources of the lexical ERP modulation in this task. B. Proactive top-down mechanism in terms of general baseline increase in object categorization. The gray and in italic "N400" indications refer to potential sources of the lexical ERP modulation in this task. C. Proactive top-down mechanism in terms of specific predictions in object naming (through picture semantics; cf. Bar, 2003). The gray and in italic "pP2" indication refer to potential sources of the lexical ERP modulation in this task. D. Proactive top-down mechanism in terms of specific predictions in object categorization (cf. Bar, 2003). The gray and in italic "N400" indications refer to potential sources of the lexical ERP modulation in this task. 


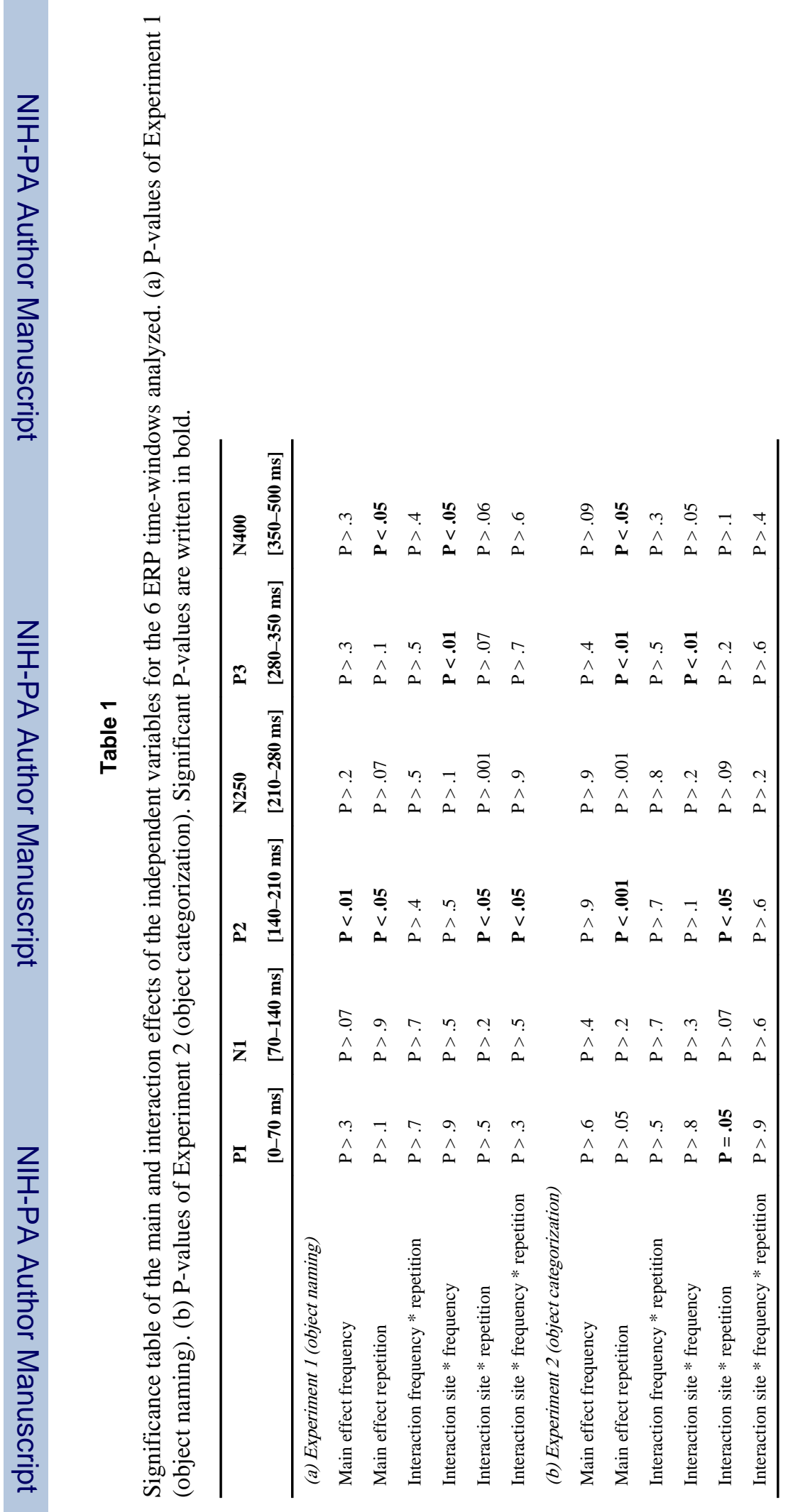

